\title{
Commentary \\ A Presentation of Ionic Liquids as Lubricants: Some Critical Comments
}

\author{
Pietro Calandra ${ }^{1, *(\mathbb{C})}$, Elisabeta I. Szerb ${ }^{2}\left(\mathbb{D}\right.$, Domenico Lombardo $\left.{ }^{3} \mathbb{(}\right)$, Vincenzo Algieri ${ }^{4}\left(\mathbb{C}\right.$, Antonio De Nino $^{4}(\mathbb{D})$ \\ and Loredana Maiuolo ${ }^{4, *(1)}$
}

1 CNR-ISMN, Via Salaria km 29.300, 00015 Monterotondo Stazione, RM, Italy

2 "Coriolan Drăgulescu" Institute of Chemistry, Romanian Academy, 24 Mihai Viteazu Bvd., 300223 Timişoara, Romania; szella73@gmail.com

3 CNR-Istituto per i Processi Chimico-Fisici, 98158 Messina, ME, Italy; lombardo@ipcf.cnr.it

4 Dipartimento di Chimica e Tecnologie Chimiche, Università della Calabria, Via P. Bucci, Cubo 12/C, 87036 Arcavacata di Rende, CS, Italy; vincenzo.algieri@unical.it (V.A.); denino@unical.it (A.D.N.)

* Correspondence: pietro.calandra@cnr.it (P.C.); loredana.maiuolo@unical.it (L.M.)

Citation: Calandra, P.; Szerb, E.I.; Lombardo, D.; Algieri, V.; De Nino, A.; Maiuolo, L. A Presentation of Ionic Liquids as Lubricants: Some Critical Comments. Appl. Sci. 2021, 11, 5677. https://doi.org/ 10.3390/app11125677

Academic Editor: Cezary Czaplewski

Received: 14 May 2021

Accepted: 15 June 2021

Published: 19 June 2021

Publisher's Note: MDPI stays neutral with regard to jurisdictional claims in published maps and institutional affiliations.

Copyright: (c) 2021 by the authors. Licensee MDPI, Basel, Switzerland. This article is an open access article distributed under the terms and conditions of the Creative Commons Attribution (CC BY) license (https:// creativecommons.org/licenses/by/ $4.0 /)$.

\begin{abstract}
Ionic liquids (ILs) are liquid materials at room temperature with an ionic intrinsic nature. The electrostatic interactions therefore play a pivotal role in dictating their inner structure, which is then expected to be far from the traditional pattern of classical simple liquids. Therefore, the strength of such interactions and their long-range effects are responsible for the ionic liquid high viscosity, a fact that itself suggests their possible use as lubricants. More interestingly, the possibility to establish a wide scenario of possible interactions with solid surfaces constitutes a specific added value in this use. In this framework, the ionic liquid complex molecular structure and the huge variety of possible interactions cause a complex aggregation pattern which can depend on the presence of the solid surface itself. Although there is plenty of literature focusing on the lubricant properties of ionic liquids and their applications, the aim of this contribution is, instead, to furnish to the reader a panoramic view of this exciting problematic, commenting on interesting and speculative aspects which are sometimes neglected in standard works and trying to furnish an enriched vision of the topic. The present work constitutes an easy-to-read critical point of view which tries to interact with the imagination of readers, hopefully leading to the discovery of novel aspects and interconnections and ultimately stimulating new ideas and research.
\end{abstract}

Keywords: lubricants; ionic liquids; self-assembly

\section{Introduction}

Friction is a very general phenomenon of energy dissipation that appears between sliding pairs [1,2]. For this reason, the reduction of friction plays a crucial role in many applications in which it is necessary to achieve the control of heat generation and of the constituents wearing out. The addition of a lubricant between two sliding solids may remarkably influence the friction even if it depends on the nature of the employed lubricant. A definition of "good lubricant" can be surely correlated to three prevalent factors:

(1) the achievement of the desired friction coefficient;

(2) the lubricant has to be able to withstand the pressure without being squeezed out;

(3) the lubrication performance should be as independent as possible of changes in the environment [3].

A correlated aspect is that it should reduce the heat generated during surface interactions in order to prevent structure deformation during these processes.

A typical lubricant is generally a mineral oil. Usually, it is added to additives, such as antioxidants, detergents, dispersants, friction modifiers, etc., to achieve other effects, such as reduction of wear, erosion, and corrosion of the contacting surfaces. 
The idea to employ ionic liquids (ILs) as synthetic lubricants was developed in 2001 [4], and several publications and patents on this topic were successively published to highlight their high-performing lubricant properties. ILs are organic salts with low melting temperatures possessing particular characteristics, such as low vapour pressure, low volatility, high thermal stability, high combustible temperature, and high miscibility with organic compounds. All these properties make ionic liquids performing lubricants or even additives to enhance the tribological properties of base oils.

In this commentary, we summarize the research efforts in recent years to apply in ionic liquids in the lubrication field, making comments on the physicochemical factors determining their peculiar performance. We can already state that self-assembly and how it can change when approaching the surface will be considered. These considerations are very important to understand the molecular-level mechanisms of dissipation across ionic liquid films and, from this, to design ionic liquid lubricants with increased tribological performance for various applications.

Even if there is much literature dealing with the lubricant properties of ionic liquids, we wish, instead, to furnish the reader with a critical view of this topic through a panoramic vision based on the physics of complex systems, avoiding detailed and sometimes casespecific descriptions, which are already available in the literature. Far from being a standard work, therefore, we try to furnish a simple but enriched vision of the topic. The present work constitutes an easy-to-read guide to young researchers to stimulate their imagination, hopefully stimulating new ideas and encouraging novel research.

Our work is mainly organized in five parts:

- Section 2 will give a general description of the properties of ionic liquids which allow their use as lubricants;

- Section 3 will show the mechanism of action of ILs as lubricants;

- $\quad$ Section 4 will give some hints on how to probe the IL structure;

- Section 5 will report some examples of the use of ILs as lubricants;

- $\quad$ Section 6, finally, will give some perspectives.

\section{Why Should ILs Be Used as Lubricants?}

Ionic liquids (ILs) may be broadly defined as molten (i.e., in liquid state) organic salts at room temperature [5]. They are composed by an organic cation and an organic (or inorganic) anion to produce an electrically neutral ion pair.

Generally, the cations are large, with long alkyl chains or a polysubstituted heteroaromatic core, while the anionic portion is relatively small. The typical IL cationic and anionic composition is reported in Figure 1.

The different size of cations and anions may be determinant for the liquid state of ionic liquids at a temperature lower than $100{ }^{\circ} \mathrm{C}[6,7]$ due to the difficulty in the building up of a regular crystal lattice. In addition, this peculiar asymmetry between the cation and anion size may favour the molecules in the fluid to self-assemble in various ways (charge-by-charge assemblies) [8], similar to liquid crystals [9] but less ordered than a typical solid crystal. This is shown in Figure 1. However, the complex pattern of anioncation piling is also influenced by other interactions of different strengths and at different extents, such as polar and apolar interactions, steric hinderance, eventual $\mathrm{H}$-bonds, and $\pi-\pi$ interactions, etc.

Thanks to this peculiar chemical property, other unique properties generally arise, such as high viscosity, negligible volatility, high polarity, nonflammability, high thermal stability, and miscibility with water and other organic solvents. 


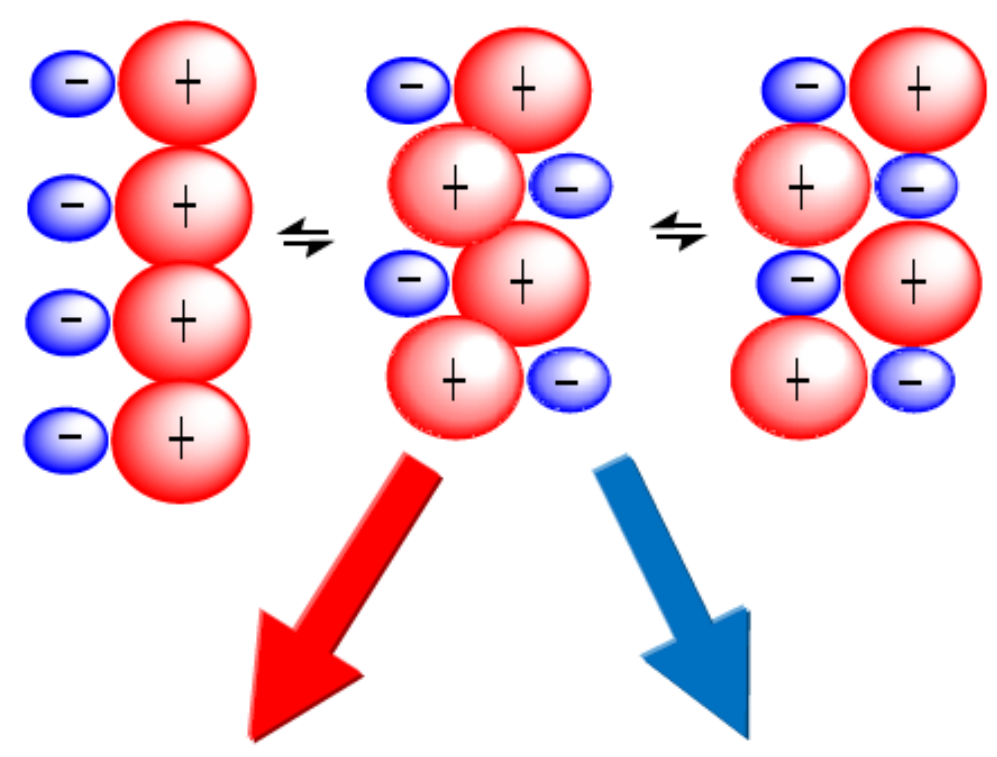

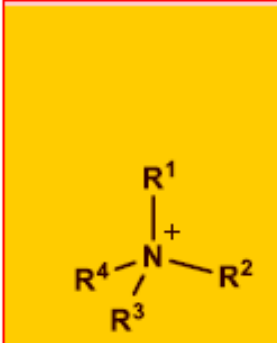

Tetraalkylammonium<smiles>[R][n+]1ccccc1</smiles>

$\mathrm{N}$-alkylpyridinium
Cations<smiles>[R][P+]([R])([R])[R]</smiles>

Tetraalkylphosphonium<smiles></smiles>

$N, N^{\prime}$-dialkylimidazolium

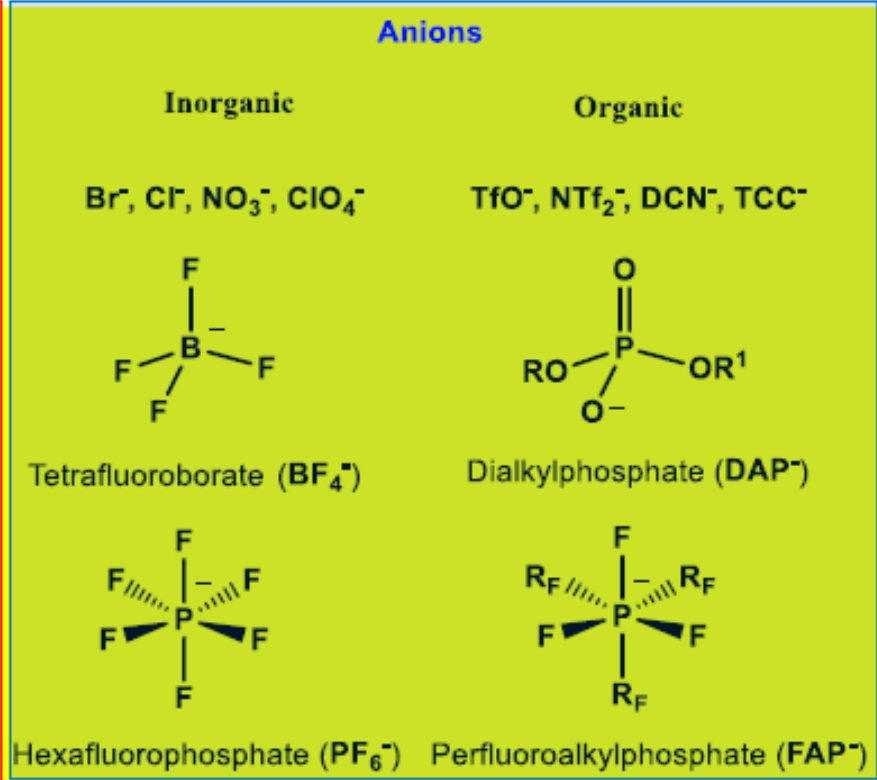

Hexafluorophosphate $\left(\mathrm{PF}_{6}{ }^{-}\right)$Perfluoroalkylphosphate (FAP')

Figure 1. Common cations and anions of ILs.

These properties make ILs good lubricants as promising alternatives to the conventional lubricants [10,11], overcoming the typical tribological problems in chemical engineering fields, such as the friction between metals or other materials and their wear [12-14]. In particular, the structure of ILs determines their high viscosity, and for this reason, they have also shown very good boundary lubricating capacity (see mechanisms of lubrication in Section 3) [15]. Another valid advantage is surely represented by the wide variety of cations and anions that can be combined to construct different ILs with tuneable properties and more flexible applications. More clearly, specific ILs can be designed and modulated to act only on the surface of sliding materials or to react with their surface or as additives to be dissolved in typical lubricants (i.e., mineral or synthetic oils). 
In any case, the key factor for the expectance of a good lubrication effect by an IL is that the electrostatic forces between anions and cations and their eventual capability to establish strong interactions with a solid surface can give the IL a better capacity to resist squeezing out from the sliding surfaces under high pressures. In brief, they can form a stable film on the surfaces held up by intermolecular interactions that are higher than the usual intermolecular interactions in conventional lubricants [16]. However, the high pressure may inhibit the aggregation of ionic liquids in macroclusters, favouring clusters of smaller sizes. This phenomenon reduces the viscosity of IL by decreasing its lubricating capacity [17-19]. However, other value-added properties arise thanks to their peculiar characteristics: the great miscibility with (or solubility in) a wide range of materials makes these important additives in lubricants. This is justified by the fact that, even if dissolved in another solvent, the strong electrostatic interactions between anions and cations of the IL allow their self-assembly within the solvent, so that the above considerations about the possibility to form a film on solid surfaces, hold up by electrostatic interactions, still holds. It is not the case that ILs can retain their lubrication performances even if dissolved up to 1:10-100 [20]. If smaller amounts of IL can be used, benefits in terms of costs are achieved [21]. Their low volatility allows them to be considered as green lubricants, avoiding the typical complications of common lubricants (i.e., in high-vacuum systems).

It must, however, be pointed out that this is just one of the "green" uses of IL in addition to their use in organic and inorganic reactions as green solvents, where their facile recovery from the reaction media allows their recycling for successive reactions [22-27]. All these, are applications which are triggered by ever-increasing attention towards environmental concerns. Moreover, the thermal stability of ILs up to $300-400{ }^{\circ} \mathrm{C}$ prevents problems concerning the decomposition of synthetic lubricants. As expected, the combination of anions, cations, alkyl chains, and the length of side chains dramatically influences the lubricant performance of ILs. Anions as $\left[\mathrm{BF}_{4}\right]^{-}$and $\left[\mathrm{PF}_{6}\right]^{-}$are the most employed, generally for their affordable costs and easily availability [28]. However, as will be discussed in the next sections, the anion structure can be changed, for example, with organic anions such as dialkylphosphate [DAP], dicyanamide [DCN], and tricyanomethane [TCC] so that the presence of fluorine-based anions (promoting undesired corrosion reactions in the presence of water) can be avoided. In any case, lubricating noncorrosion-resistant materials can be made by ILs with other organic anions containing fluorine (i.e., trifluomethanesulfonate [TfO], bis(trifluoromethylsulfonyl)imide [NTF2], and perfluoroalkylphosphate [FAP] anions) [29]. Pyrrolidinium, pyridinium, and imidazolium cations affect the viscosity of ionic liquids, under the same anions and lateral chains, which is a property crucial for the thickness of lubricants [30]. For instance, the combination of imidazolium and phosphate groups may increase the lubricating performance of ILs, significantly reducing friction and wear challenges. Moreover, the length of the side alkyl chain is very determinant for the tribological properties of ILs due to the different alignment of ionic liquids with short or long alkyl chains under an electrical field [31]. As it can be deduced from the above introduction, the interest in ILs as lubricants must be addressed, in our opinion, to their peculiar chemical nature which provides a complex behaviour. This causes, in addition to the bare increased viscosity usually exploited in lubrication, further emerging properties to arise which are of added value (see Figure 2) and which cannot be found in conventional lubricants. 
MAIN (DRIVING) PROPERTY

High viscosity

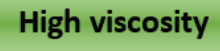

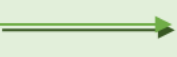

lubrication

\section{ADDED-VALUE PROPERTIES}
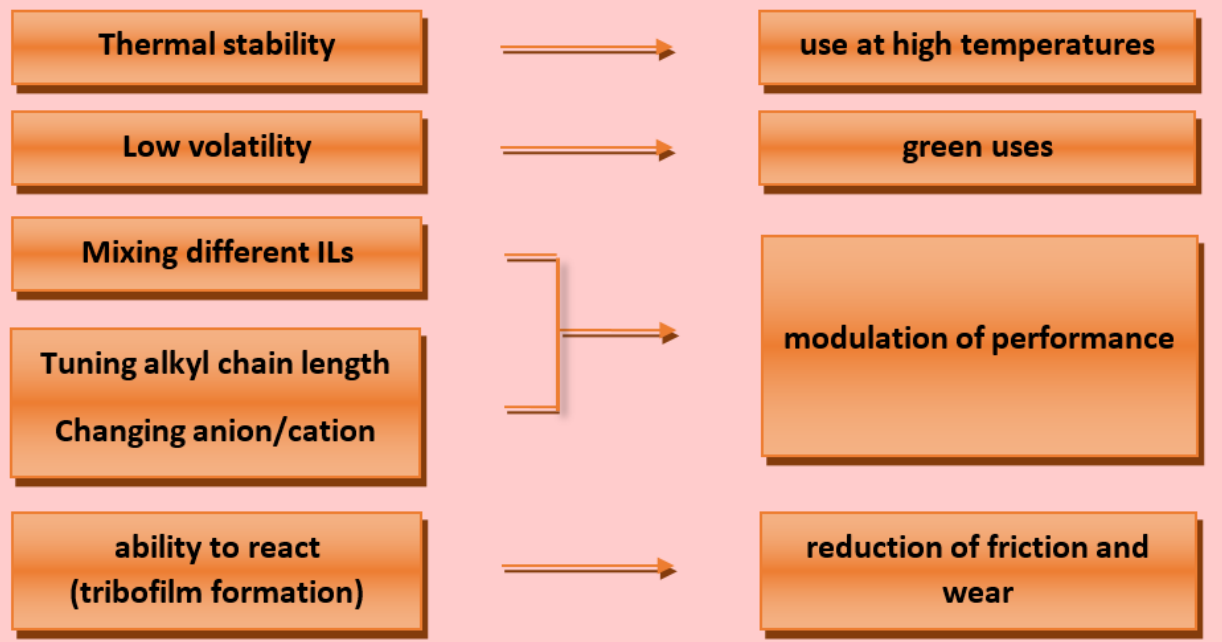

Figure 2. Schematic collection of the IL properties for lubrication purposes.

\subsection{Surface-Dependent IL Structure}

The structure of an IL is peculiar. By the term structure we mean the existence of preferential distances between constituents. In a simple liquid, the position of molecules can be influenced only by interactions taking place at short distances, so the preferential distance is generally that at which the first coordination shell forms, all higher distances being almost equally probable [32]. On the other hand, in ionic liquids, signatures of the mesoscopic order occur. In particular, it has been suggested (see the example given by imidazolium-based ionic liquid [33]) that nanoscale structural heterogeneities in the bulk liquid state are caused by the segregation of long enough apolar alkyl chains into domains which are embedded into a three-dimensional charged matrix generated by the positively and negatively charged heads [34]. This feature has also been found in alcohols and their mixtures [35] and also in liquid surfactants and their mixtures, whose structure is rationalized in terms of the coexistence of polar/apolar domains instead of positive/negative domains as in ionic liquids [36]. Generally speaking the tendency of intermolecular structure formation takes place when intermolecular interactions become strong enough to overcome thermal agitation. This can even give rise to self-segregation. It is clear that intermolecular interactions become increasingly stronger in the order of excluded volume, apolar interactions, polar interactions, $\mathrm{H}$-bonds, and electrostatic interactions, so an increasingly higher structure with the increasing ionic liquid character is expected. However, it must be remembered that, in soft matter, parallel with the intensity of the interactions involved, a key factor is the number density of interactions. It can happen, in fact, that a high number of soft interactions can give rise to a significant structure, as in soft matter and bio-related materials, where a slight difference in temperature can induce striking changes in the structure. In our case, the interactions between IL and the contacting surface can be of the same strength (or even stronger) than the interactions present in pure IL 
and characterizing the inner (bulk) part of the ionic liquids. This can cause a dramatic structural change when approaching the contacting surface. This is schematically depicted in Figure 3.

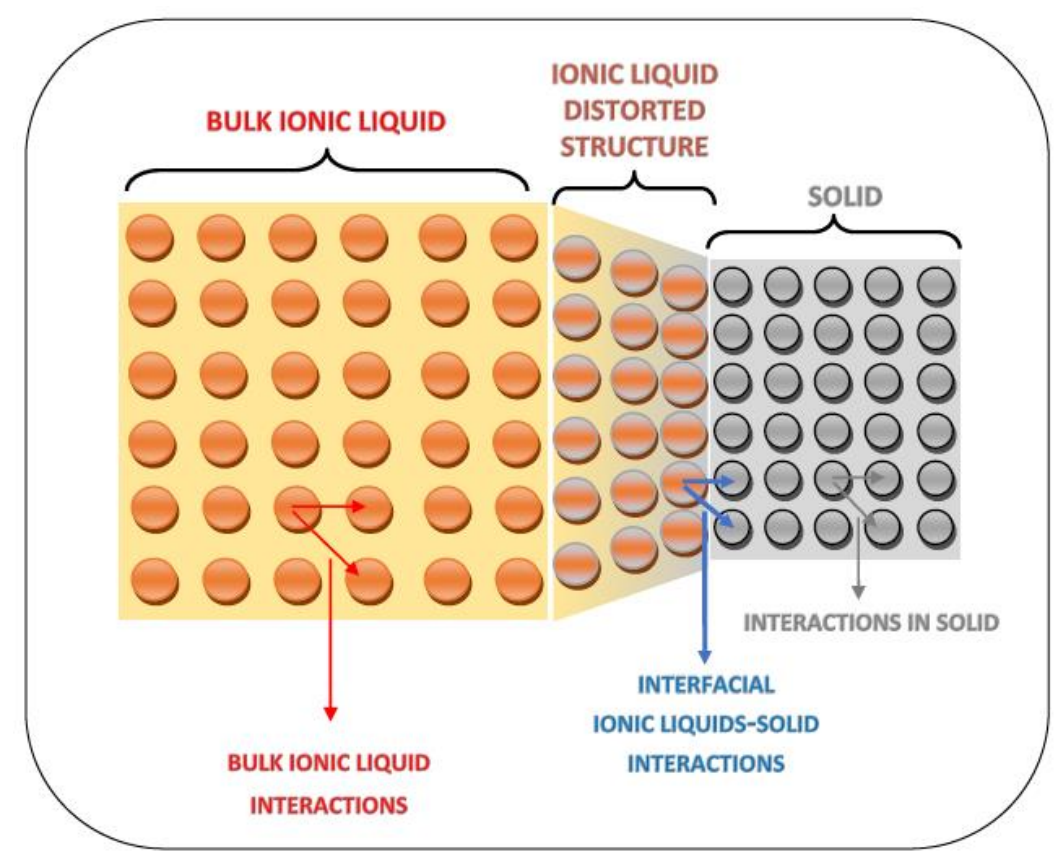

Figure 3. IL structure close to a surface.

The structure of an IL is therefore not invariant, since it can depend on the material that needs to be lubricated. Its function, therefore, must be addressed to the complex combination of IL properties and the potential interactions with the contacting material needing lubrication.

In this context, it is interesting to notice that the recent developments of self-assembly processes in nanoscience are already providing innovative well-defined smart materials linking soft matter chemistry to hard matter sciences. This is the key point of this work: the ionic liquid structure (soft matter) is related to the solid surface (hard matter) when approaching the interface, which is a fundamental aspect in lubrication.

\subsection{Moving Closer to the Surface}

The chemistry of solid-liquid interfaces is often very different from that of bulk liquids. This is because, close to the interface, the structure and dynamics of solvent molecules are altered $[37,38]$.

The spatial distribution of solvent molecules or ions at solid-liquid interfaces is a central problem in science: in addition to the IL interface interactions, we envisage many other fields where this is true, such as in (amphiphile) adsorption, colloid stability, heterogeneous catalysis, charge transfer, and protein folding [39-43].

However, the importance of the order at a surface should be clear if biointerfaces are considered, where the structure precisely controls functions governing life processes [44].

As neatly and schematically depicted in the review by Hayes et al. [45], near the surface, ILs exhibit oscillatory density profiles consistent with ion pair (anion + cation) or bilayer $(2 \times$ ion pair) dimensions [46-50]. This structuring is of a fundamentally different origin to solvation layers in molecular liquids [51-53] or ABAB packing in molten salts [54-57] because IL ions have the capacity to self-assemble. This provides additional impetus to ion structuring over and above simple geometric constraints (in molecular liquids) or charge ordering (in molten salts). The near-surface organization of ions is best described as layered or lamellar-like and, in many respects, parallels that found in adsorbed surfactant layers [58,59] but on smaller length scales. 


\subsection{Specificity of Surfaces}

Even in the first application of ILs as lubricants, evidenced by Ye et al. in 2001, who used alkylimidazolium tetrafluoroborates to lubricate steel, aluminium, copper, silica crystal, and ceramics, the influence of the chemical composition of the surface already emerged [4]. In that work, the authors used 1-hexyl-3-methylimidazolium tetrafluoroborate and 1-ethyl-3-hexylimidazolium tetrafluoroborate to test the reduction of friction and wear phenomena in a ball-on-disc system (Figure 4).<smiles></smiles>

[HMIM][BF4]: $\mathrm{R}=\mathrm{Me} \quad \mathrm{R}^{1}=n-\mathrm{C}_{6} \mathrm{H}_{13}$ [EMIM][BF4]: $\mathrm{R}=\mathrm{Et} \quad \mathrm{R}^{1}=n-\mathrm{C}_{6} \mathrm{H}_{13}$<smiles>CC(C)(C(F)(F)F)C(C)(C)C(F)(F)C(F)(F)C(F)(F)C(F)(F)C(F)(F)F</smiles>

Perfluoropolyether (PFPE)

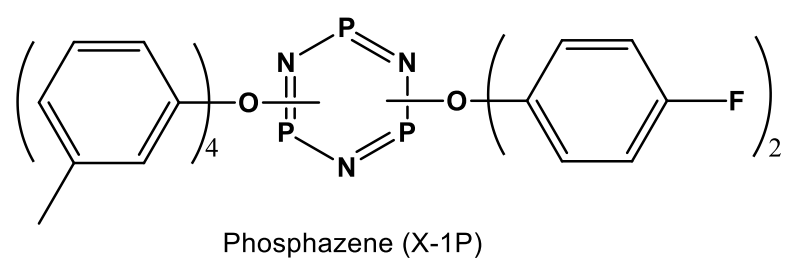

Figure 4. Chemical structure of alkylimidazolium tetrafluoroborates and traditional lubricants.

The results of ILs compared with two classical fluorine-containing lubricants, phosphazene (X-1P) and perfluoropolyether (PFPE), are reported in Table 1 . The values, aside from highlighting a promising and versatile lubricant effect of ILs, show bigger \% changes in the friction coefficient as a function of the materials of the frictional disk. This clearly suggests a major dependence of IL lubrication performance on the surface material. Moreover, harsh conditions of friction can promote the decomposition of the tetrafluoroborate anion to form fluoride active as an antiscratch component.

Table 1. Friction coefficients for various sliding pairs lubricated with some lubricants (load $50 \mathrm{~N}$, frequency $25 \mathrm{~Hz}$, amplitude $1 \mathrm{~mm}$ ).

\begin{tabular}{cccc}
\hline \multirow{2}{*}{$\begin{array}{c}\text { Frictional Pair } \\
\text { (Ball/Disk) }\end{array}$} & \multicolumn{3}{c}{ Friction Coefficient } \\
\cline { 2 - 4 } & [HMIM][BF4] & X-1P & PFPE \\
\hline Steel/Steel & 0.065 & 0.098 & 0.145 \\
Steel/Al & 0.040 & 0.128 & - \\
Steel/Cu & 0.025 & 0.117 & 0.145 \\
${\text { Steel/ } \mathrm{SiO}_{2}}_{\text {Steel/sialon }}^{0.060}$ & 0.110 & 0.132 \\
\hline
\end{tabular}

\section{Mechanism of Action of ILs as Lubricants}

The typical action of lubricants is attributable to the formation of a film as a thin layer that can effectively reduce the friction between surfaces and their consequent wear. It is now understood that the high lubricating action of ILs is strongly due to the type of film formed on materials in contact. Substantially, two sorts of lubrications occur when two surfaces are in real contact and adhesion and a friction phenomenon is present: hydrodynamic lubrication and boundary lubrication (see Figure 5a,c for the schematic mechanism), although it is obvious that a hybrid of the two can also take place (Figure $5 b$ ). 


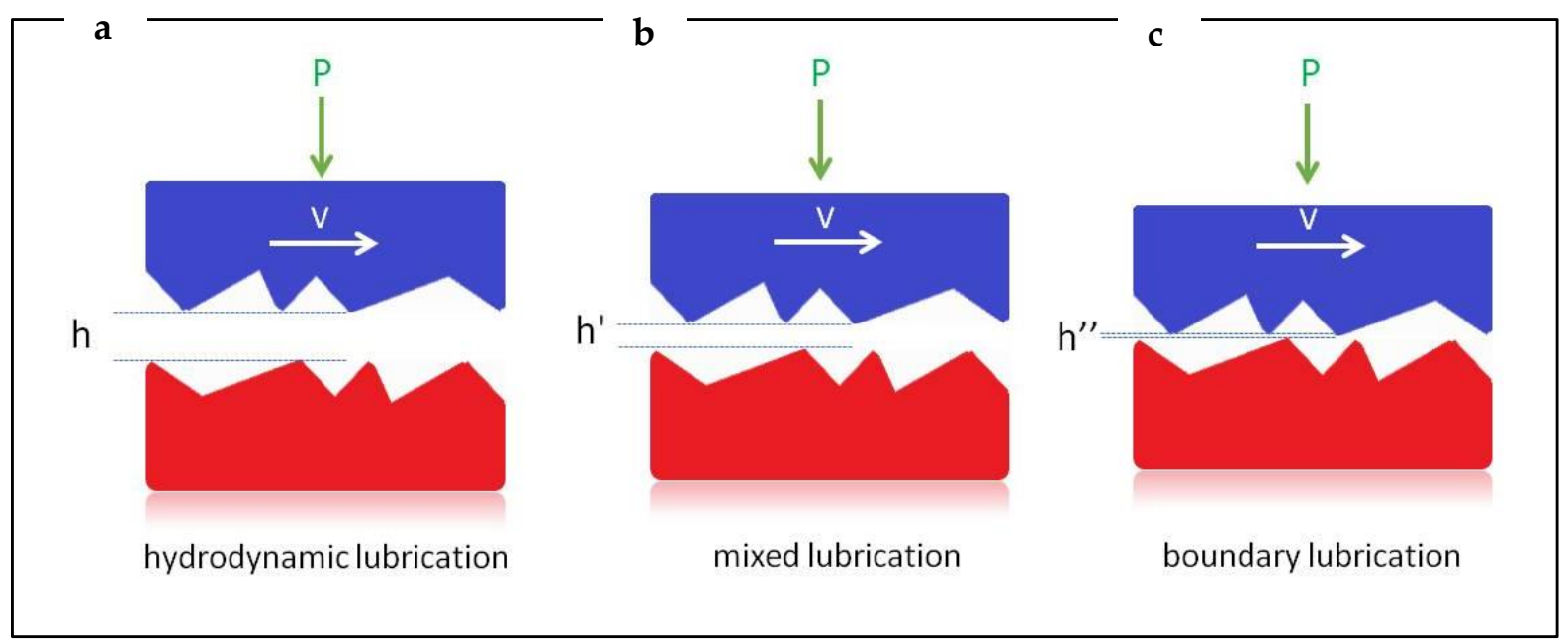

Figure 5. Representation of the main mechanisms of lubrication: (a) boundary lubrication, (b) mixed lubrication, and (c) hydrodynamic lubrication. P: pressure; V: velocity.

\subsection{Hydrodynamic Lubrication (HL)}

Hydrodynamic lubrication takes place when two surfaces move perpendicularly toward each other, and a thicker layer of lubricants is added to penetrate the interaction zones to prevent physical or direct contact between them and to reduce rubbing, friction, and wear phenomena. In fact, if the fluid is convergent to the direction of motion, it adheres to the sliding surface as a viscous film that builds up pressure sufficient to carry the load (Figure 5a) [60].

This lubrication process is the core of efficient functioning of the whole modern industry. It is clear that the high viscosity of ILs becomes the dominant property with regard to their lubricant action. However, if we take the viscosity index as the only parameter to compare ILs and mineral (or synthetic) oils, high variations are not observed. In Table 2, the viscosity index of some ionic liquids and base oils are reported.

The interest in ILs as lubricants, instead, is to be traced back to other factors, which will, step by step, be commented on in what follows. For example, we can already introduce, here, that ILs are particularly fit for tuning the overall viscosity by simply mixing two of them. This is not trivial, since usually the mixing of two fluids can lead to nonideal mixing and nonlinear behaviour, with the possible overall reduction of the performances due to the interactions of the two constituents. In our opinion, in the case of a mix of two ionic liquids with the same cation, the interactions of the two constituents reduce to the interactions between the anions only, which are inherently reduced since they are separated by the positively charged cations. Our speculative consideration is actually supported by some experimental works: a work of Koyama et al. proved that a mix of two ionic liquids with

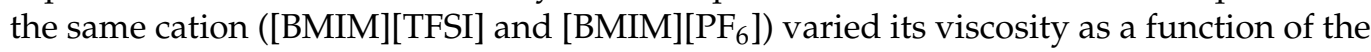
mixing ratio [61-63]. This experimental observation has opened up a new scenario in the field of ILs as lubricants because it stands to reason that the adjusting of the viscosity can be accomplished by mixing several types of ionic liquids, also recalling their low vapour pressure and high thermal stability. 
Table 2. Viscosity index of some ionic liquids and base oils at different temperatures.

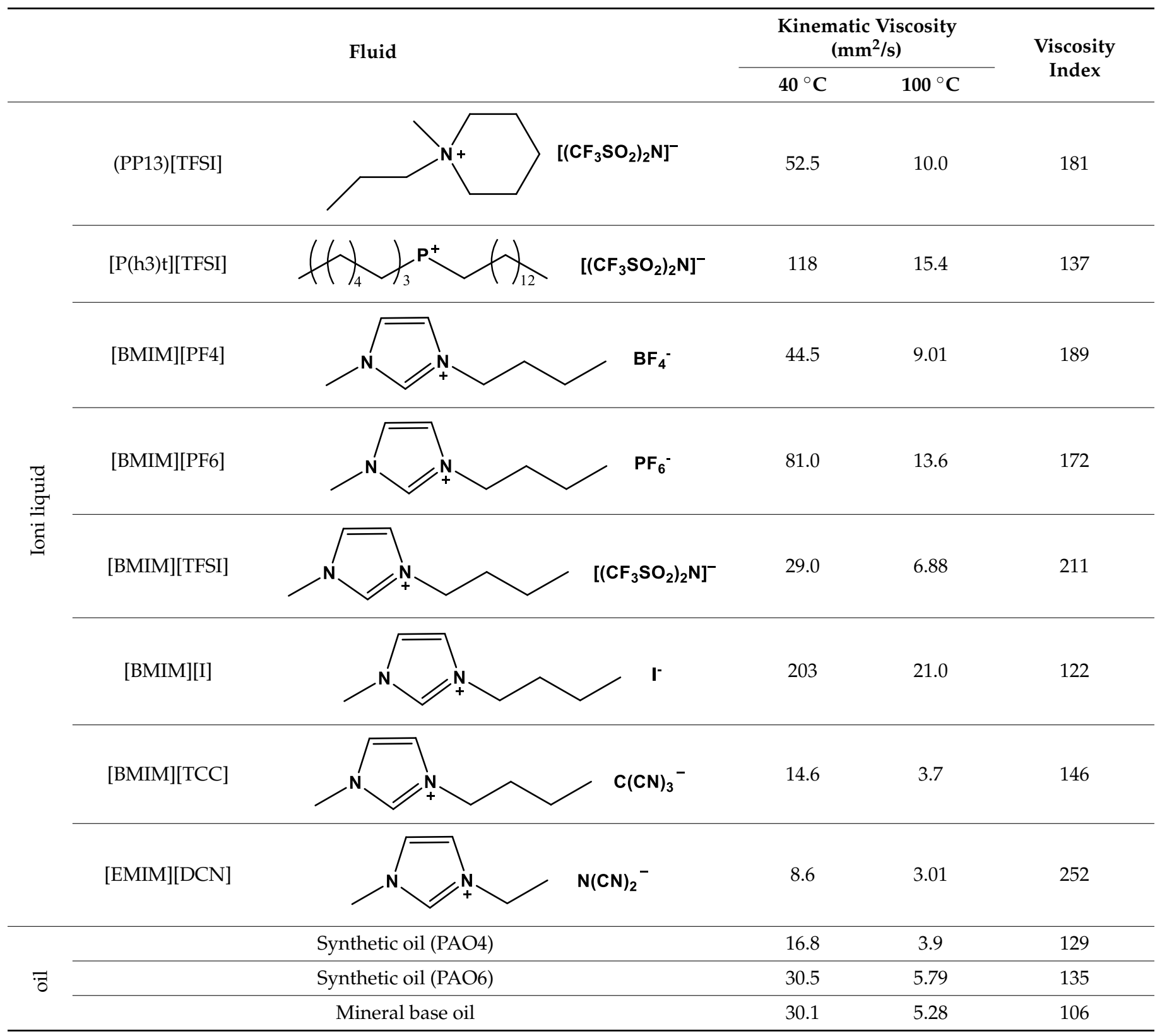

One development of hydrodynamic lubrication is the elastohydrodynamic lubrication (EHL) that is prevalently utilised for friction pairs with elastic contact, such as ball bearings and gears. In this case, the thickness of the lubricant is smaller than that of hydrodynamic lubrication, and the elastic deflection of the surfaces in contact shall be taken into to account. Under these circumstances, the predominant physical property for lubrication is the viscosity under high pressure that is measured for some methylimidazole-substituted ionic liquids, which is similar to liquid crystals under high pressure [64].

\subsection{Boundary Lubrication (BL)}

Boundary lubrication occurs when the sliding surfaces are so close that the superficial interactions between films of lubricants and the asperities of the materials dominate the contact (see Figure 5c).

This lubrication offers two different typologies of protective films: (1) adsorbed layers, which have a low shear rate promoting a better sliding between surfaces and (2) protective layers that derive from chemical reactions of ILs with the surfaces. In more detail, for the 
second mechanism, the tribochemical reactions may be promoted by temperature and pressure contact. In fact, the friction between two surfaces produces the conversion of mechanical energy into heat with the generation of local high temperatures. This allows the emission of electrons and of other particles (i.e., ions, lattice components, etc.) [65]. The reaction of emitted electrons with lubricants adsorbed on a surface may produce anions and radicals that are really responsible for its lubrication. A general study of Kajdas et al. about the anionic-radical lubrications due to the action of low-energy electrons indicates that the negative ions produced by the exoelectron emission are chemisorbed on the positively charged friction microareas of metallic surfaces (or ceramics), furnishing an organometallic (or inorganic) protecting tribofilm for them (Figure 6, left panel) [66].
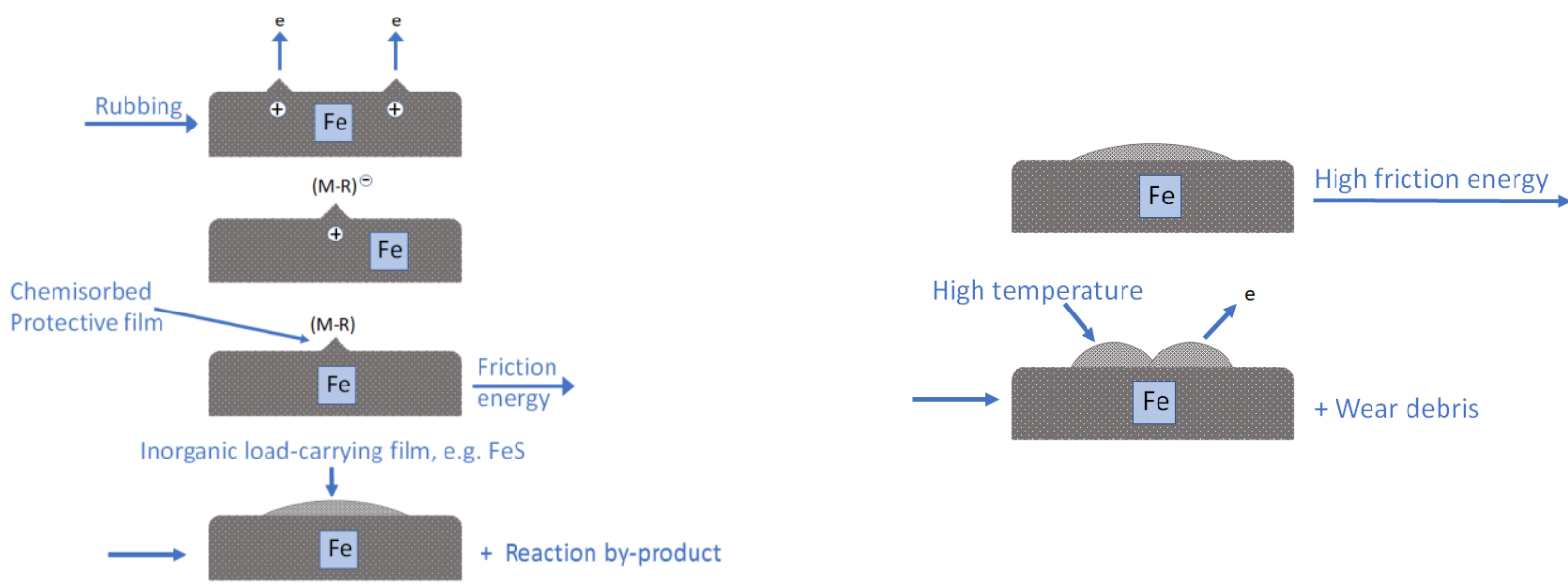

Figure 6. Process of (left panel) exoelectron emission (EEE) and of (right panel) destruction of the lubricant film and formation of activated surface spots.

In addition, the local high temperature of friction destructs the created lubricant layer and generates activated surface spots, forming a new protective film (Figure 6, right panel).

In this framework, it is clear that the physics of the IL no longer plays a pivotal role, and the chemical/reactive aspect of the molecules involved needs to be taken into account. It is interesting to notice that, in this case, the assumption that the lubricating fluid needs to be an inert material is no longer valid, a consideration that needs to be pointed out for a panoramic vision of the overall phenomenon of lubrication.

\subsection{Mixed Lubrication (ML)}

Of course, the aforementioned mechanisms are the two extreme points of view of a mechanism that can be, in principle, a complex one, being a hybrid of the two. In this case, mixed lubrication is usually dealt with: it is a regime in which two (or even more, in principle) lubrication mechanisms are functioning spontaneously. In this context, there are some portions of the surfaces that are in contact and others that remain separated by a partial hydrodynamic fluid film due to a smaller film thickness. Therefore, the load is supported partly by the contact asperities and partly by the pressurized hydrodynamic film (Figure 5b).

Usually, in many works, the goodness of a certain lubricating fluid under specific mechanisms is emphasized. Statements such as "ionic liquids show excellent tribological performance in regime of boundary lubrication" are common in the literature. However, we want to stress that the lubricating fluid can determine the mechanism of friction, especially if the sliding surfaces are relatively free to move apart. It has recently been shown that the structures close to the surface, and in particular the number and lateral structure of ion layers confined between the sliding surfaces, dictate the lubricity performance [67]. This means that the combination of the IL intrinsic structure and the influence of the interactions with the surface control the nanoscale friction and, reasonably, the mechanism. To better 
understand this idea, the study by Wong et al. in 2018 can help. These authors investigated the application of ILs as additives to polyethylene glycol (PEG) used as a base fluid [68]. They observed that the film thickness increased with the increasing IL concentration as an additive, although the friction was slightly reduced. Therefore, in the ML lubrication, the addition of IL can reduce the problems related to friction and wear in mild conditions, forming layers protecting the sliding surfaces.

\section{Intermolecular Distances as Probes for Structure: How to Measure Them}

Generally speaking, from an experimental point of view, the study of a material requires the employment of techniques and approaches that simultaneously investigate the structural properties and dynamics of nanomaterials at the nanoscale $[69,70]$.

The characterization of the structural features and the elucidation of the self-assembly processes occurring in a given material, indeed, are important pieces of information requested when studying the relationships between physical properties and specific involved soft interactions [71-74], which is the final goal of any material scientist. More specifically, the term "structure" is directly related to the existence of preferential distances: this, in principle, is directly probed by scattering techniques, but other techniques can be used.

\subsection{Scattering}

Scattering techniques are among the most employed experimental techniques for the investigation, in noninvasive way, of the structural properties of materials and complex self-assembly processes [75-77] in a large variety of material systems and different reactive environments [78], at least in the bulk phase.

There are plenty of works dealing with such techniques, so the reader is redirected to the literature for details. Here, however, we just want to remind the reader that a peak in the scattering spectrum (reciprocal or q-space) equals a peak in the distances (real or R-spaces) according to a simple relation: $\mathrm{R}=2 \pi / \mathrm{q}$.

Figure 7 , reporting the comparison between the scattering spectra of a simple liquid (propylamine) and an IL, can shed light on this.

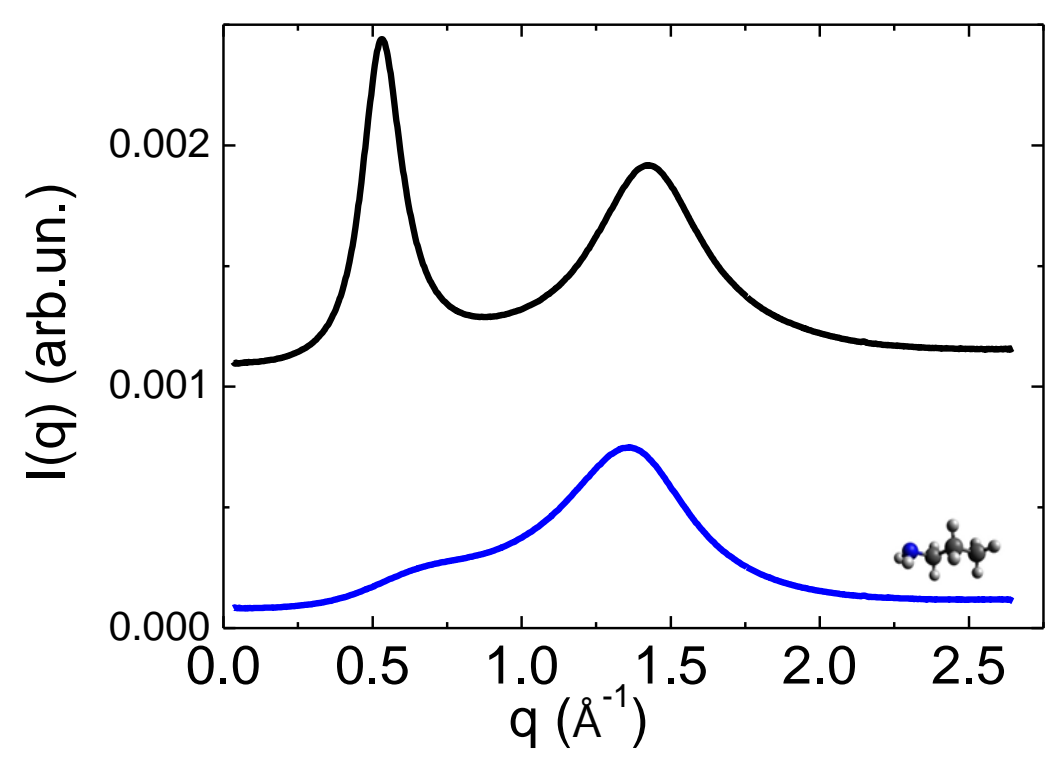

Figure 7. Scattering patterns of a classical liquid (propylamine, with weak intermolecular interactions, lower plot) and an ionic liquid (a 1:1 mixture of propylamine and dibutylphosphate, upper plot).

In the IL scattering pattern, the broad band at wide angles (about $1.4 \AA^{-1}$ ) are due to the intermolecular short range distance taking place between first neighbouring molecules and due to intermolecular spacings of about $4.5 \AA$, typical of the conventional liquid state [79]. This signal is generally found for any liquid. In the case of ILs, however, another 
band occurs at lower q values $\left(\mathrm{q} \approx 0.5 \AA^{-1}\right)$, revealing the occurrence of an intermolecular association in a pattern already known in the past for $n$-alcohols [80,81] and liquid amphiphiles [82-84].

The presence of associated species causes a new characteristic repetition distance to arise, in the present example, of about $13 \AA$, which may be identified with the characteristic distance of polar/polar domains typical of ILs [31]. This is a quite universal signature in ionic liquids: generally, an X-ray peak below $1 \AA^{-1}$ (and usually quite sharp) can be considered as a signature of the mesoscopic order [85] and is usually characteristic of such systems [86,87]. In particular, as found for imidazolium-based ILs [28], but also for alcohols and their mixtures [30], the low-q contribution in the spectrum comes from the nanoscale structural heterogeneities in the bulk liquid state caused by the segregation of long enough apolar alkyl chains into domains which are embedded into a three-dimensional charged matrix generated by the positively and negatively charged heads [29]. It must be noted that the impact of temperature in such patterns is scarce [88].

However, due to the liquid nature of the system, rapid molecular and charge association/fission processes take place, so the repetition distances we are discussing are to be meant as a time- and space-averaged distance with a characteristic polydispersion.

It must be noted that a faint bump around $0.8 \AA^{-1}$ is usually present and, although several structural features can contribute to this scattering signal, it is generally recognized as coming from charge-charge interactions, i.e., cation-anion characteristic distance repeating in the bulk [89]. This signal is generally quite weak (in Figure 7, for example, it is almost undetectable) and is generally associated with the sponge-like structure expected to be made by the charged groups [90].

\subsection{Atomic Force Microscopy (AFM)}

When dealing with the structure near a surface, the information is more difficult to obtain, and different techniques are used. In the case of atomic force microscopy (AFM), the lateral organization of molecular liquids and adsorbed ions on solid substrates with subnanometer resolution can be elucidated (see works by Voïtchovsky et al., such as [35] and [91]). In the case of ILs, high-precision soft contact amplitude modulation (AM-) AFM experiments are particularly fitting, with papers probing the structure for both protic [61,92] and aprotic $[93,94]$ ILs next to a surface. We believe that AFM, being sensitive to forces, is the ideal technique for probing both the distances and the forces involved in molecular layers close to a surface.

If metal surfaces are considered, it must be noticed that, in general, papers that probe solvent structure at metal interfaces are geared toward the polarized electrode surfaces to understand the IL electrical double layer structure. This is due to the fact that unlike in molecular liquids, [95] the atomic resolution of surface structure by scanning tunnelling microscopy (STM) in an IL has not been achieved. This is most likely due to the strong ion adsorption onto the tip in an STM experiment, blurring surface features [42]. AFM tips remain an effective proof especially with the aid of MD simulations. However, more sophisticated techniques have been sometimes used like TPPE (femtosecond two photon photoemission spectroscopy) [96] or SFG (sum frequency generation spectroscopy) [97], but of course these are quite specific and unusual methods so we cannot but admit that a lack of standardized routine methods still holds.

\subsection{Purity Dictates Structure}

The structure in ILs is a delicate affair. Changes can be triggered even by a small amount of foreign substances, as a signature that the overall structure is a delicate balance of several types of interactions in a complex pattern. This feature has been observed by Mariani et al. [98] who, studying transport properties in ionic liquids, detected the possibility of marked and unusual changes in the viscosity when a given solvent (acetonitrile) is added to the IL ethylammonium nitrate. This was of course a consequence of a local structural change and was reasonably attributed to micelles formation. The steep decrease 
in viscosity when a cosolvent is added was also observed by Seddon et al. [99]. Similar situations have been found in mixtures of amphiphiles where a small amount of propylamine to dibutylphosphate or, inversely, the addition of small amount of dibutylphosphate to propylamine does not lead to the same structural perturbation, highlighting a nonsymmetrical effect.

\section{Some Applications}

In this section, some applications will be presented and commented on with special attention to the most recent ones (in the last decade). Considering applicative aspects and the marked dependencies of ILs performance on the chemical nature of the surfaces to which they come into contact, the examples will be primarily grouped according to the material of the surface to be lubricated. Secondarily, within the applications related to each single material, the different problematics will be presented and commented on.

\subsection{Steel Surfaces}

\subsubsection{The Initial Efforts to Find Performing ILs as Lubricants}

The emergent use of ionic liquids since the 2000s as lubricating materials of the challenging contacts of metals collided immediately with their preparation costs. Therefore, with regard to researching ionic liquids with low costs, Lawes et al. proposed some ILs with a choline chloride cation [100]. Choline chloride is an organic compound that is widely used as a vitamin supplement in poultry and pig feed, and for this reason, it can be found easily at low cost. Two choline chloride-based ILs were proposed by changing only the chloride anion. They were termed ethaline (choline chloride-ethylene glycol 1:2 ratio) and reline (choline chloride-urea 1:2 ratio), respectively (Figure 8).

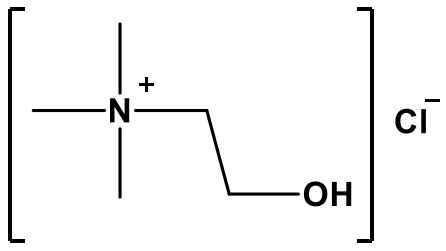

(a)<smiles>OCCO</smiles>

(b)<smiles>NC(N)=O</smiles>

(c)

Figure 8. Chemical structures of (a) choline chloride, (b) ethylene glycol, and (c) urea.

Wear tests were conducted under low-speed/high-load and high-speed/low-load between two sliding steel surfaces, observing a low friction coefficient comparable to a classical lubricant (5W30 engine oil), but that increased over time until resulting in dry sliding with the rise of the sliding surface distance.

These partially disappointing results, probably due to failure to maintain the boundary film, showed, in any case, an interesting application of highly available ILs, which still requires an optimization.

\subsubsection{Developments through Preparation of ad hoc ILs}

Another application of steel-steel lubrication was promoted by Zhu et al. that explored four ILs with imidazolium derivatives containing an ester group as a cation [101]. The twostep synthetic procedure involves the initial alkylation of a nitrogen of imidazole ring and subsequent metathesis reaction to substitute the $\mathrm{Cl}^{-}$anion with others. (Figure 9). 


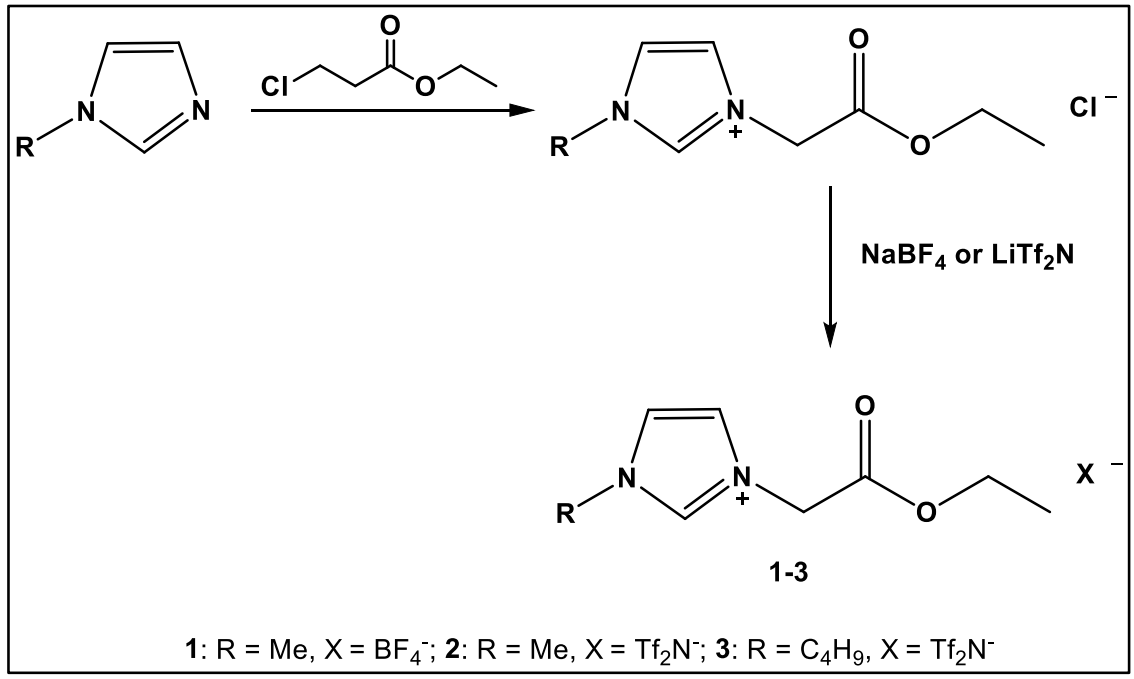

Figure 9. Synthesis of imidazolium ILs.

The tribological performance of these ILs was evaluated for a steel ball-disc contact area, and the friction coefficient was compared to a commercial lubricant PFPE for different loads. The results are reported in Table 3 and demonstrated that all employed ILs were superior to PFPE in terms of the reduction of friction and wear for steel-steel contact.

Table 3. Friction coefficients measured for steel/steel frictional pairs by ionic liquids and PFPE ${ }^{\text {. }}$

\begin{tabular}{ccccc}
\hline \multirow{2}{*}{ Load/N } & \multicolumn{4}{c}{ Friction Coefficient } \\
\cline { 2 - 5 } & IL 1 & IL 2 & IL 3 & PFPE \\
\hline 100 & 0.086 & 0.094 & 0.095 & 0.131 \\
200 & 0.077 & 0.081 & 0.085 & 0.138 \\
400 & 0.076 & 0.082 & 0.077 & 0.122 \\
600 & 0.082 & 0.085 & 0.074 & $-\mathrm{b}$ \\
800 & 0.079 & 0.082 & 0.075 & $-\mathrm{b}$ \\
\hline
\end{tabular}

a Friction coefficient measured at $25^{\circ} \mathrm{C}^{\mathrm{b}}{ }^{\mathrm{b}}$ No lubrication.

In particular, the chemical structure of ILs can justify the behaviour of these compounds as excellent lubricants because when the IL has a triflate group as an anion, a major capacity to avoid wear is observed, and ILs with a longer alkyl chain reduce friction better than those containing shorter alkyl chains. This latter result may be a direct consequence of the increase of viscosity with the increase in chain length, which constitutes a good example of how the lubrication properties can be tuned by changing the alkyl chain length, as already introduced in Section 2.

The above examples show that the main strategy for IL preparation is synthetic chemistry. This is quite complicated and has high costs. In addition to setting up efficient synthetic protocols and triggering mass-scale production, new strategies are clearly needed to radically change the paradigms of IL preparation. For example, considering that for the preparation of several ILs, a final step of metathesis in which the primary anion (generally a halide) is exchanged with the final selected anion is necessary, the possibility to project and realize synthetic one-step methodologies, or those with a low number of reaction steps, may surely reduce production costs and make the process ecocompatible. In any case, we will show some perspectives in this sense in the final sections.

\subsubsection{Anion Effects}

That, beyond the cation feature, the anion can also make a real difference towards the tribological activity of ILs has been confirmed by a study by García et al. in which the authors use three ILs as neat lubricant for steel-steel contact [102]. More specifically, 
the tested ILs were: (1) [(NEMM)MOE][FAP] ethyl-dimethyl-2-methoxyethylammonium tris(pentafluoroethyl)trifluoro-phosphate, (2) [BMP][FAP] 1-butyl-1-methyl-pyrrolidinium tris(pentafluoroethyl)trifluoro-phosphate, and (3) [BMP][NTF2] 1-butyl-1-methylpyrroli dinium bis(trifluoromethylsulfonyl)imide. The investigations were conducted at 40 and $100{ }^{\circ} \mathrm{C}$ on steel discs, and the [BMP][NTF2] showed the better antifriction coefficient at $40^{\circ} \mathrm{C}$, though at $100^{\circ} \mathrm{C}$, its tribological behaviour as a friction inhibitor was considerably decreased due to its lower prevalent viscosity than the corresponding IL with a FAP anion (Figure 10).

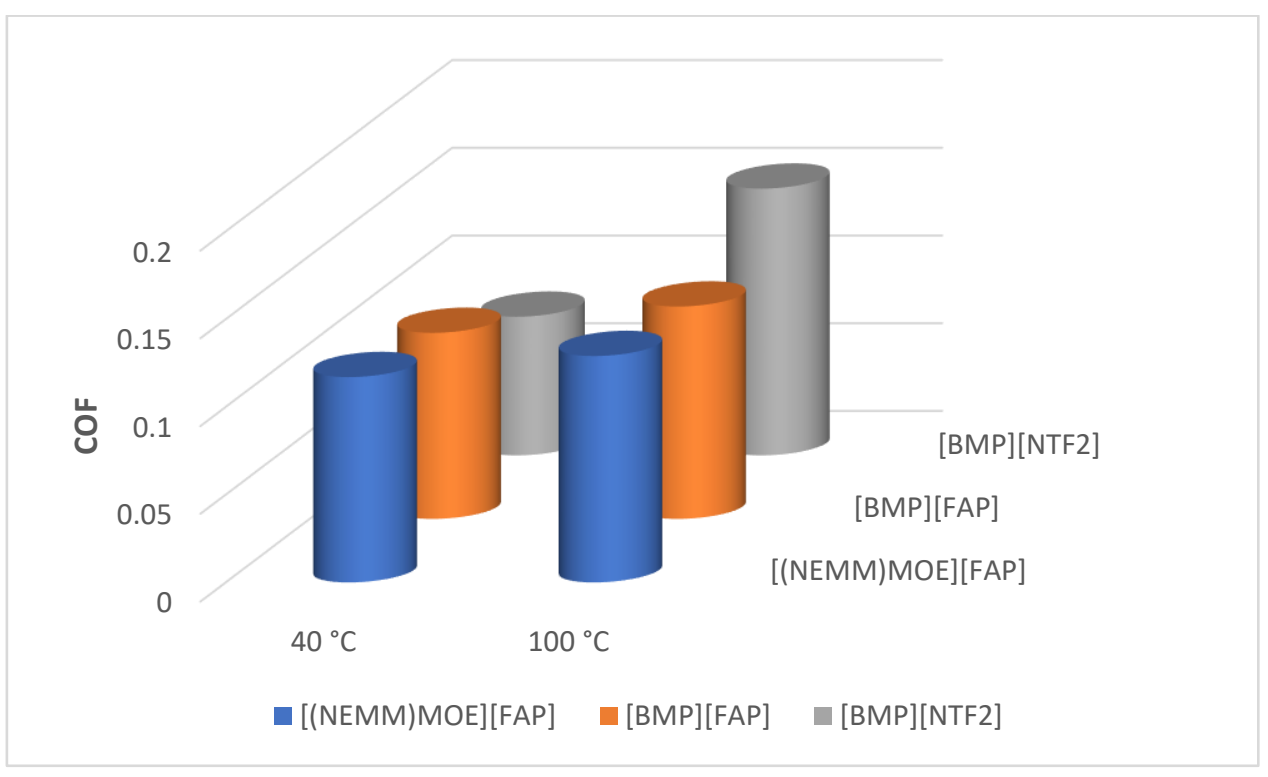

Figure 10. Average coefficient of friction (COF) of [(NEMM)MOE][FAP], [BMP][FAP], and [BMP][NTF2] at 40 and $100{ }^{\circ} \mathrm{C}$.

In our opinion, this confirmation is somehow expected, since anions and cations are specular actors in the framework of electrostatic interactions, although, in practise, they have different sizes in ionic liquids. In fact, in this case, it is not so strange to think that the distinct chemical nature of the perfluoroalkylphosphate (FAP) and the bis(trifluoromethylsulfonyl)imide (NTF2) groups allows interactions with probable different strengths between ILs and the contacting surface to be invoked.

\subsubsection{Low-Vapour Pressure}

The advantageous properties of ILs and, in particular, their low-vapour pressure makes them interesting for testing purposes in extreme conditions, such as high vacuum and low temperatures to which space mechanisms are subjected. Common lubricants used in space are generally based on perfluorinatedpolyethers (PFPE), such as Fomblin ${ }^{\circledR}$ Z25 [103]. In 2019, its tribological properties were compared to seven purchased or synthesized ionic liquids with different chemical structures [104]. Among all tested lubricants, almost all ILs showed good antifriction and wear-resistance properties, but only an IL based on 1-butyl-1-methyl-pyrrolidiniumbis(trifluoro-methylsulfonyl)amide (named IL2 in that work) widely overcame the performance of the reference lubricant, as illustrated in Figure 11. Lifetime experiments (long-term lubricity and endurance in vacuum) confirmed the excellent results of IL2, even if it showed an insufficient fluidity at a low temperature. It is clear that this is a weak point for its lubricating applicability in space, considering the extreme conditions to which mechanism parts are subjected, and therefore, it is worth thinking about how it is necessary to study the largest number of ILs with tuneable properties. 


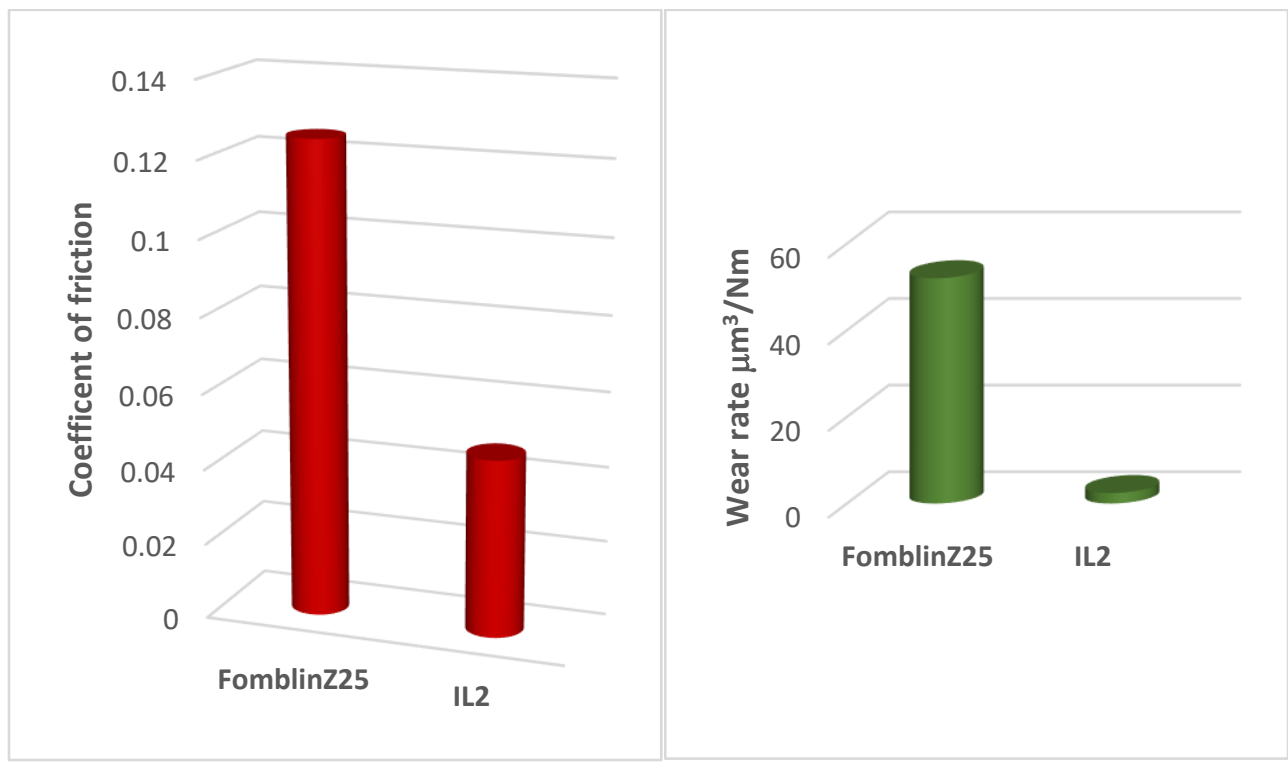

Figure 11. Coefficient of friction and wear rate of Fomblin Z25 compared to IL2.

\subsubsection{Magnetic Ionic Liquids}

Magnetic ionic liquids (MILs), ionic liquids, generally, with an organic cation and a magnetic anion (i.e., with a single electron organic free radical or metal ion complex), may be easily magnetized and used as lubricants of steel-steel sliding pairs. In contrast to traditional magnetic fluid lubricants (MFs), MILs have an excellent high temperature stability and a very low volatility, giving them important tribological properties [105]. For this reason, recently, Jia et al. [106] synthesized a magnetic ionic liquid $\left(\left[\mathrm{C}_{6} \mathrm{mim}\right]_{5}\left[\mathrm{Dy}(\mathrm{SCN})_{8}\right]\right)$ in which the cation is 1-hexyl-3-methylimidazolium and a dysprosium (Dy) is the metallic centre of the anion complex (Figure 12).<smiles></smiles>

Figure 12. Magnetic ionic liquid with 1-hexyl-3-methylimidazolium as cation and a dysprosium complex as anion.

The authors tested their MIL on rubbed steel surfaces, comparing it with a classical MF composed of DIOS (dioctyl sebacate) and $\mathrm{Fe}_{3} \mathrm{O}_{4}$. The results of the coefficient of friction (COF) conducted at different temperatures showed a better and permanent friction reduction by the synthesized MIL at high temperatures and loads. Moreover, the wear volumes of a steel-steel sliding contact lubricated by the MIL and MF at variable temperatures and loads were measured, demonstrating the almost constant results of wear inhibition only by lubrication with $\left[\mathrm{C}_{6} \mathrm{mim}\right]_{5}\left[\mathrm{Dy}(\mathrm{SCN})_{8}\right]$.

\subsection{Aluminium Surfaces}

Aluminium is widely used in the automobile and aerospace industries [107]. In these applications, aluminium is often subjected to problems due to the sliding of moving components because of its poor tribological properties that make the system difficult to lubricate. For this reason, different types of lubricants are employed to reduce friction and wear, and in particular, protic ionic liquids (PILs) were found to be very promising [108]. More recently, PILs based on 2-hydroxyehtylamine (2HEA) and a carboxylic acid (formic 
and pentanoic acids) (Figure 13) were synthesize by Vega et al. to study, among other aspects, the effect of anion chain length on the lubrication of aluminium parts [109].

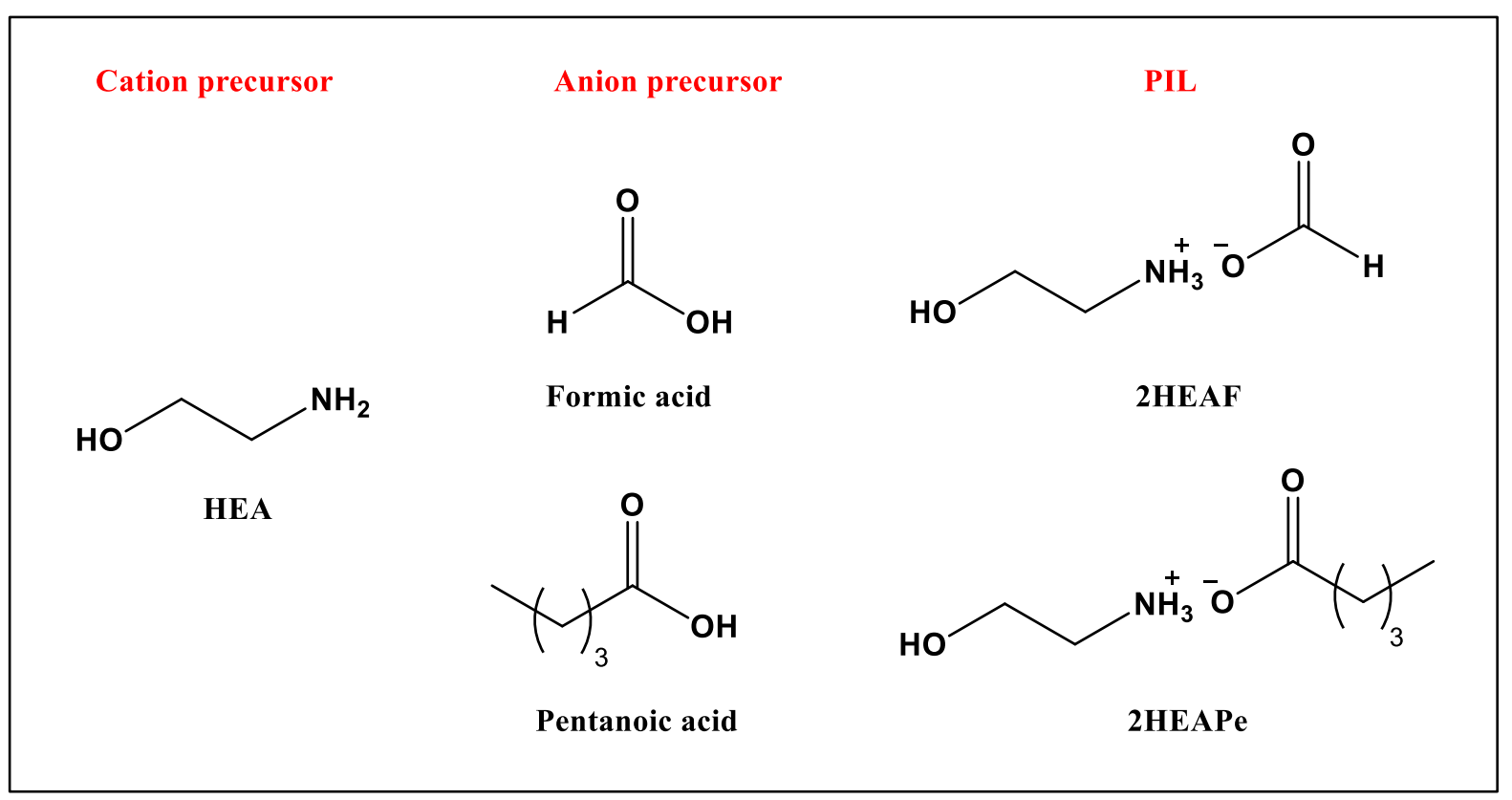

Figure 13. Structure of synthesized PILs and their precursors.

The PILs were compared to a commercial lubricant, and the results of the coefficients of friction are grouped into Table 4.

Table 4. Coefficient of friction value of two synthetized PILs.

\begin{tabular}{cc}
\hline Lubricant & Cefficient of Friction \\
\hline Commercial & $0.08 \pm 0.011$ \\
2HEAPe & $0.14 \pm 0.026$ \\
2HEAF & $0.35 \pm 0.12$ \\
Dry & $0.64 \pm 0.10$ \\
\hline
\end{tabular}

The coefficients of friction measured for an aluminium-steel system showed that the 2HEAPe gave value similar to that of commercial lubricant, highlighting the better ability of the protic IL with a longer chain to support a major load. This example confirms the important role exerted by the length of the alkyl chain, offering a way to effectively control the coefficient of friction by simply tuning the number of $\mathrm{C}$-atoms involved in the chain. However, the performance of 2HEAPe suffers from the distance of sliding surfaces because the lubricant regime is based on the boundary lubrication; therefore, the instability and oscillation of the COF were observed when the distance of surfaces was increased. An elongation of the alkyl chain of the anionic portion might amplify the interactions between chains or with the surface metal, permitting, for example, a wider stacking or micelle-like arrangement that may reflect a wider adjustment to the several lubrication mechanisms.

In confirmation of the effect of alkyl chain length in changing the tribological properties of IL lubricants, a study conducted by Zhang et al. on imidazolium ILs with variable alkyl chains (Figure 14) highlighted that (1) the derivatives with the longest chain of cations (hexyl and octyl imidazolium ILs) showed a better-performing lubricating activity; (2) different anions did not alter the results; (3) in the sliding process the more active ILs provided an excellent boundary film, which is very important for antiwear performance; and (4) the temperature did not influence the tribological action of the examined lubricants [110]. 


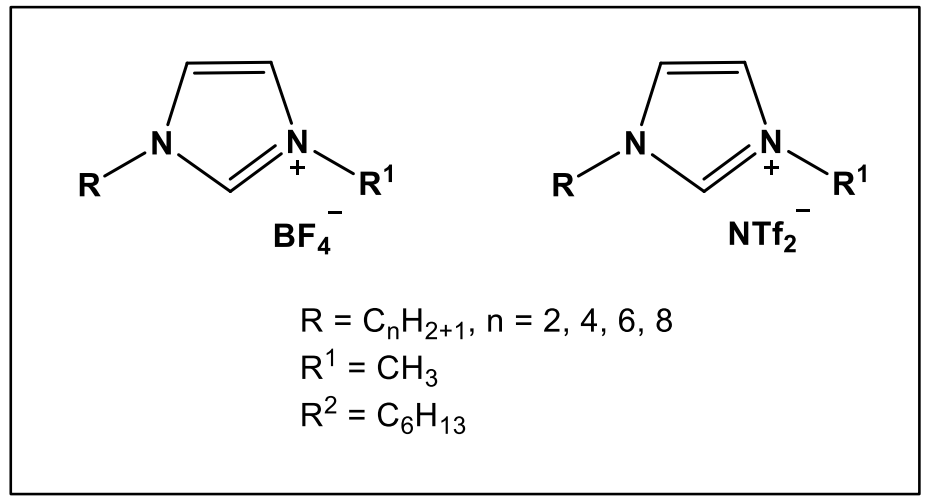

Figure 14. Structure of imidazolium ILs with variable alkyl chain.

In 2018, the lubricating ability of PILs on aluminium-steel contact was studied by the use of tri-[bis(2-hydroxyethylammonium)]citrate (DCi) (Figure 15) as an additive to mineral oil (MO) [111].

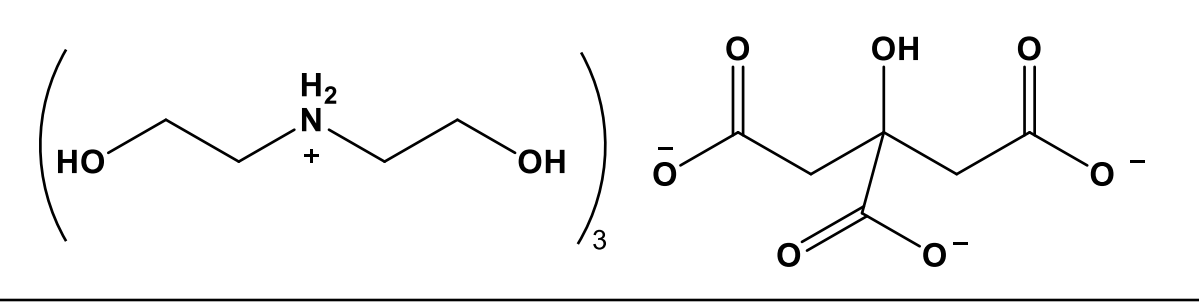

Figure 15. Structure of tri-[bis(2-hydroxyethylammonium)]citrate (DCi).

Three sliding velocities $(0.10,0.15$ and $0.20 \mathrm{~m} / \mathrm{s})$ were used to compare the lubricating performance of MO with respect to MO mixed with $1 \mathrm{wt} \%$ or $2 \mathrm{wt} \% \mathrm{DCi}$. The friction coefficient and wear volume were reduced for each sliding velocity, prevalently at $0.15 \mathrm{~m} / \mathrm{s}$ and a $\mathrm{MO}+2 \%$ DCi solution with which friction and wear decreases of $16 \%$ and $40 \%$, respectively, were observed (Figure 16).

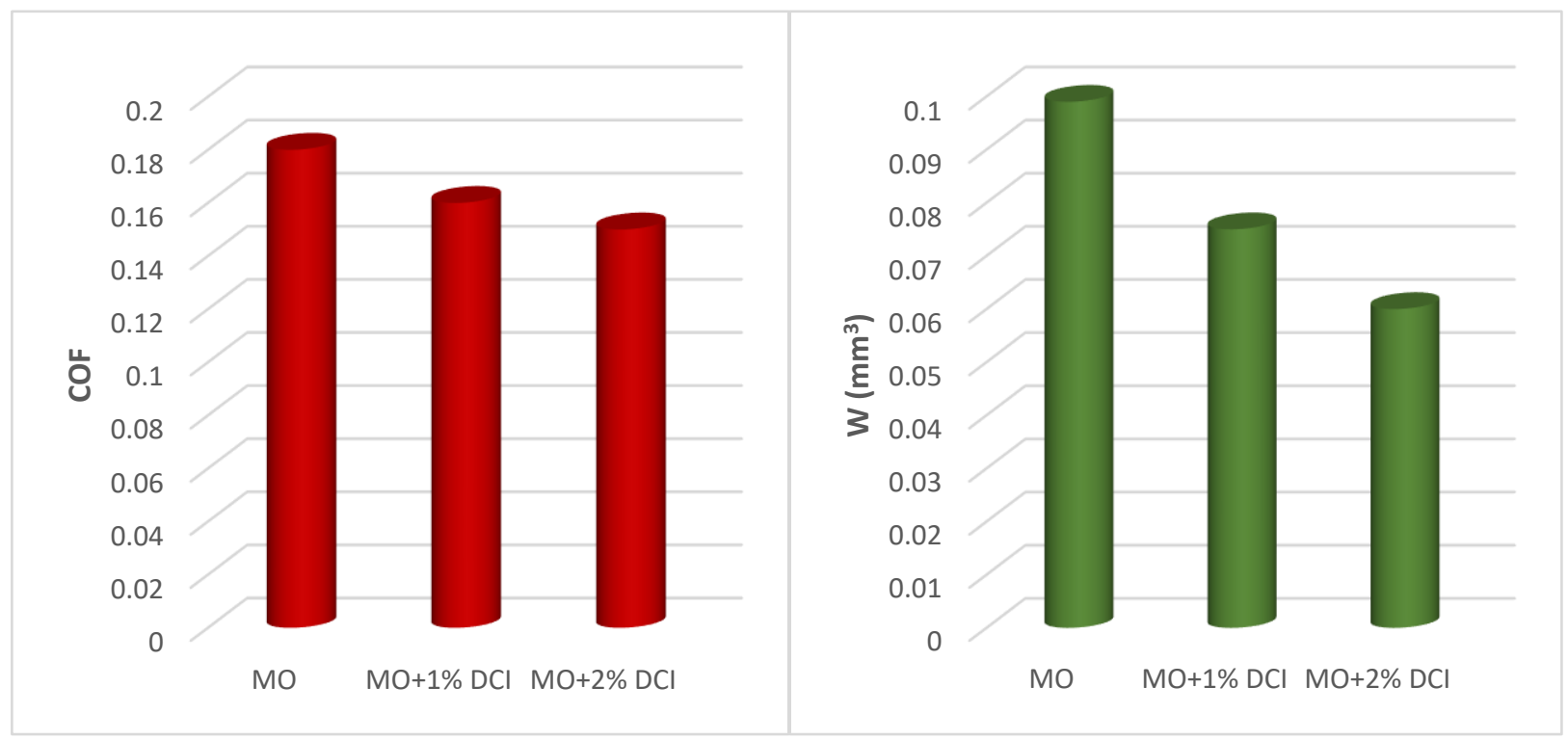

Figure 16. Fiction coefficient and wear volume for different concentrations at sliding velocity of $0.15 \mathrm{~m} / \mathrm{s}$. 


\subsection{Titanium}

Titanium is an attractive material with wide applications in industry due to a high strength and excellent resistance to corrosion and wear. In fact, an oxidized titania layer is generally present on the titanium surface, preventing material wear [112]. However, a critical problem of titanium use is its poor lubrication capacity with classical lubricants. Considering the high affinity of ILs for solid surfaces and their robust boundary layers, $\mathrm{Li}$ et al. investigated mixtures of IL trihexyl- (tetradecyl)phosphonium bis(2,4,4trimethylpentyl)phosphinate with hexadecane at different concentrations [113]. As already discussed, sometimes the costs of production of ILs can be a limitation in using ILs as lubricants, and for this reason, ILs as an additive can be often a valid solution for industrial applications. The researchers showed that pure IL and some IL/hexadecane mixtures at different loads remarkably reduced the friction coefficient compared to pure hexadecane and to its mixture with a traditional antiwear additive (zinc-dialkyl-dithophosphate; ZDDP) (Table 5).

Table 5. Lubrication activity at different load of hexadexane and its mixture with IL and ZDDP.

\begin{tabular}{ccc}
\hline \multirow{2}{*}{ Lubricant } & \multicolumn{2}{c}{ Friction Coefficient } \\
\cline { 2 - 3 } & $\mathbf{2 N}$ & $\mathbf{1 0 N}$ \\
\hline Hexadecane (HD) & $0.45 \pm 0.05$ & $0.46 \pm 0.05$ \\
HD + 0.01\% IL & $0.46 \pm 0.04$ & $0.47 \pm 0.04$ \\
HD + 0.1\% IL & $0.47 \pm 0.05$ & $0.48 \pm 0.04$ \\
HD + 1\% IL & $0.45 \pm 0.05$ & $0.46 \pm 0.05$ \\
HD + 2\% IL & $0.11 \pm 0.02$ & $0.45 \pm 0.06$ \\
HD + 10\% IL & $0.12 \pm 0.02$ & $0.47 \pm 0.05$ \\
Pure IL & $0.09 \pm 0.01$ & $0.09 \pm 0.01$ \\
2\% ZDDP & $0.42 \pm 0.06$ & $0.45 \pm 0.04$ \\
\hline
\end{tabular}

In 2019, four quaternary phosphonium ILs with variable structures (Figure 17) were selected as a titanium lubricant, considering that quaternary phosphonium-based ILs can easily be dissolved in apolar hydrocarbon oils, including mineral oil, and are generally very stable [114].

Consequently, they show optimal tribological characteristics both as pure components and as diluted in hydrocarbon oils. In particular, the friction reduction seems to be strongly dependent on IL viscosity because the less viscous $\mathrm{P}_{6,6,6,14}$ TFSI was, the more effective IL was for macrotribology performance in a mixed lubrication regime (Table 6). On the contrary, in nanotribology tests, only the structure of the ILs was really important; in fact, the cation of $\mathrm{P}_{8,8,8,6(2)} \mathrm{BEHP}$ adsorbed better to the titanium surface, forming a resistant film that minimized the energy dissipation. On the other hand, this different behaviour is not surprising, because both the variable alkyl chains of cations and the chemical structure of the bis-trifluoromethylsulfonyl)imide (NTF2) anion, which is different than other ILs characterized by phosphate and phosphonate groups, can dramatically affect both their chemical-physical properties and their chemical interactions with the sliding surface.

Table 6. Friction coefficients of some ILs used as lubricants.

\begin{tabular}{cc}
\hline IL & Friction Coefficient \\
\hline $\mathrm{P}_{8,8,8,6(2)} \mathrm{BEHP}$ & 0.08 \\
$\mathrm{P}_{6,6,6,6,14} \mathrm{BEHP}$ & 0.33 \\
$\mathrm{P}_{6,6,6,6,14}\left({ }^{\mathrm{i}} \mathrm{C}_{8}\right)_{2} \mathrm{PO}_{2}$ & 0.16 \\
$\mathrm{P}_{6,6,6,6,14}$ TFSI & 0.17 \\
\hline
\end{tabular}




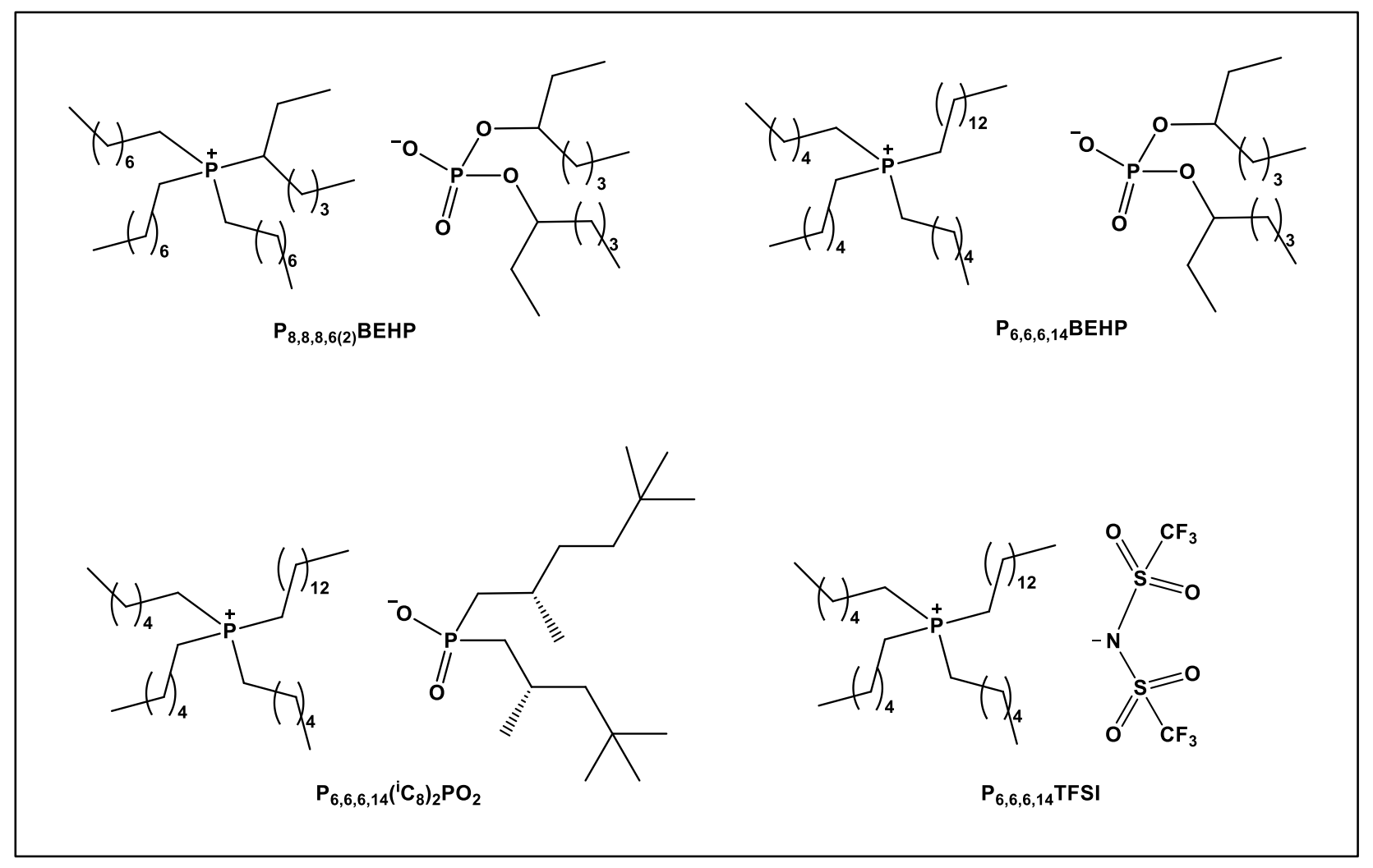

Figure 17. Chemical structure of quaternary phosphonium-based ILs used as titanium lubricant.

\subsection{Other Applications I: Magnetic Media}

Magnetic recording systems have been very important for the wide diffusion of music, videos, and information at low cost. Although a change of paradigm is currently occurring with the growing uses of solid-state devices which offer better performance, the interest in magnetic devices is still maintained due to the lower costs per storage capacity unit. In current hard disk drive (HDD) systems, a rigid disk is rotated at a speed of up to 10,000 revolutions per minute (rpm) [115]. Generally, the rigid disk is composed from an Al-Mg alloy or glass substrate, undercoat sheet, a magnetic multilayer, a carbon coverage, and a very fine lubricant layer. In particular, the carbon overcoat is necessary to prevent wear and corrosion problems, even if this activity is mainly carried out by the thin lubricant that must reduce the contact between the read/write magnetic head and the media surface. Perfluoropolyether (PFPEs) lubricants have so far been the best lubricating system for magnetic media, even if Kondo et al. have, over time, developed synthetic methodologies to prepare ILs, possessing both a perfluoroalkyl group and an ester, amide, and carboxylic acid ammonium salt with a long chain (Table 7) [116].

The authors justified the increased performance of lubricants by these class of ILs with the uniform coverage of the rubbing surface by the ammonium salt portion and a higher dispersive interaction of their hydrophobic group, combining characteristics typical for high lubrication due to secondary interactions of various kinds between contacting surfaces and polar heads and apolar chains of the cation and anion portions. 
Table 7. Composition of perfluoropolyethers (PFPEs) lubricants.

\begin{tabular}{|c|c|c|}
\hline \multicolumn{3}{|c|}{$\mathrm{R}_{\mathrm{F}}-\mathrm{CO}-\mathrm{Y}-\mathrm{R}$} \\
\hline RF & $\mathbf{Y}$ & $\mathbf{R}$ \\
\hline $\mathrm{C}_{7} \mathrm{~F}_{15}$ & $\mathrm{O}$ & $\mathrm{C}_{18} \mathrm{H}_{37}$ \\
\hline $\mathrm{C}_{7} \mathrm{~F}_{15}$ & $\mathrm{O}$ & $\mathrm{C}_{18} \mathrm{H}_{37}$ \\
\hline $\mathrm{C}_{7} \mathrm{~F}_{15}$ & $\mathrm{NH}$ & $\mathrm{C}_{18} \mathrm{H}_{37}$ \\
\hline $\mathrm{C}_{7} \mathrm{~F}_{15}$ & NH & $\mathrm{C}_{18} \mathrm{H}_{37}$ \\
\hline $\mathrm{C}_{7} \mathrm{~F}_{15}$ & $\mathrm{O}^{-} \mathrm{NH}_{3}^{+}$ & $\mathrm{C}_{18} \mathrm{H}_{37}$ \\
\hline $\mathrm{C}_{7} \mathrm{~F}_{15}$ & $\mathrm{O}^{-} \mathrm{NH}_{3}^{+}$ & $\mathrm{C}_{18} \mathrm{H}_{37}$ \\
\hline $\mathrm{C}_{9} \mathrm{~F}_{19}$ & $\mathrm{O}^{-} \mathrm{NH}_{3}^{+}$ & $\mathrm{C}_{18} \mathrm{H}_{37}$ \\
\hline $\mathrm{C}_{9} \mathrm{~F}_{19}$ & $\mathrm{O}^{-} \mathrm{NH}_{3}{ }^{+}$ & $\mathrm{C}_{18} \mathrm{H}_{37}$ \\
\hline $\mathrm{C}_{9} \mathrm{~F}_{19}$ & $\mathrm{O}^{-} \mathrm{NH}_{3}^{+}$ & $\mathrm{C}_{18} \mathrm{H}_{37}$ \\
\hline $\mathrm{C}_{9} \mathrm{~F}_{19}$ & $\mathrm{O}^{-} \mathrm{NH}_{3}^{+}$ & $\mathrm{C}_{18} \mathrm{H}_{37}$ \\
\hline$-\mathrm{CF}_{2} \mathrm{O}-\left(\mathrm{CF}_{2} \mathrm{O}\right)_{\mathrm{m}}-\left(\mathrm{CF}_{2} \mathrm{CF}_{2} \mathrm{O}\right)_{\mathrm{n}}-\mathrm{CF}_{2} \mathrm{O}-$ & $\mathrm{O}^{-} \mathrm{NH}_{3}^{+}$ & $\mathrm{C}_{18} \mathrm{H}_{37}$ \\
\hline$-\mathrm{CF}_{2} \mathrm{O}-\left(\mathrm{CF}_{2} \mathrm{O}\right)_{\mathrm{m}}-\left(\mathrm{CF}_{2} \mathrm{CF}_{2} \mathrm{O}\right)_{\mathrm{n}}-\mathrm{CF}_{2} \mathrm{O}-$ & $\mathrm{O}^{-} \mathrm{NH}_{3}{ }^{+}$ & $\mathrm{C}_{18} \mathrm{H}_{37}$ \\
\hline$-\mathrm{CF}_{2} \mathrm{O}-\left(\mathrm{CF}_{2} \mathrm{O}\right)_{\mathrm{m}}-\left(\mathrm{CF}_{2} \mathrm{CF}_{2} \mathrm{O}\right)_{\mathrm{n}}-\mathrm{CF}_{2} \mathrm{O}-$ & $\mathrm{O}^{-} \mathrm{NH}_{3}^{+}$ & $\mathrm{C}_{18} \mathrm{H}_{37}$ \\
\hline$-\mathrm{CF}_{2} \mathrm{O}-\left(\mathrm{CF}_{2} \mathrm{O}\right)_{\mathrm{m}}-\left(\mathrm{CF}_{2} \mathrm{CF}_{2} \mathrm{O}\right)_{\mathrm{n}}-\mathrm{CF}_{2} \mathrm{O}-$ & $\mathrm{O}^{-} \mathrm{NH}_{2}\left(\mathrm{CH}_{3}\right)^{+}$ & $\mathrm{C}_{18} \mathrm{H}_{37}$ \\
\hline$-\mathrm{CF}_{2} \mathrm{O}-\left(\mathrm{CF}_{2} \mathrm{O}\right)_{\mathrm{m}}-\left(\mathrm{CF}_{2} \mathrm{CF}_{2} \mathrm{O}\right)_{\mathrm{n}}-\mathrm{CF}_{2} \mathrm{O}-$ & $\mathrm{O}^{-} \mathrm{NH}\left(\mathrm{CH}_{3}\right)_{2}^{+}$ & $\mathrm{C}_{18} \mathrm{H}_{37}$ \\
\hline$-\mathrm{CF}_{2} \mathrm{O}-\left(\mathrm{CF}_{2} \mathrm{O}\right)_{\mathrm{m}}-\left(\mathrm{CF}_{2} \mathrm{CF}_{2} \mathrm{O}\right)_{\mathrm{n}}-\mathrm{CF}_{2} \mathrm{O}-$ & $\mathrm{O}^{-} \mathrm{NH}_{2}\left(\mathrm{C}_{18} \mathrm{H}_{37}\right)^{+}$ & $\mathrm{C}_{18} \mathrm{H}_{37}$ \\
\hline$-\mathrm{CF}_{2} \mathrm{O}-\left(\mathrm{CF}_{2} \mathrm{O}\right)_{\mathrm{m}}-\left(\mathrm{CF}_{2} \mathrm{CF}_{2} \mathrm{O}\right)_{\mathrm{n}}-\mathrm{CF}_{2} \mathrm{O}-$ & $\mathrm{O}^{-} \mathrm{NH}_{2}\left(\mathrm{C}_{6} \mathrm{H}_{5}\right)^{+}$ & $\mathrm{C}_{18} \mathrm{H}_{37}$ \\
\hline $\mathrm{F}-\left(\mathrm{CF}_{2} \mathrm{CF}_{2} \mathrm{CF}_{2} \mathrm{O}\right)_{\mathrm{n}^{-}}-\mathrm{CF}_{2} \mathrm{CF}_{2^{-}}$ & $\mathrm{O}^{-} \mathrm{NH}_{3}^{+}$ & $\mathrm{C}_{18} \mathrm{H}_{37}$ \\
\hline $\mathrm{F}-\left(\mathrm{CF}_{2} \mathrm{CFO}\right)_{\mathrm{n}^{-}}-\mathrm{CF}_{2^{-}}$ & $\mathrm{O}^{-} \mathrm{NH}_{3}{ }^{+}$ & $\mathrm{C}_{18} \mathrm{H}_{37}$ \\
\hline
\end{tabular}

\subsection{Other Applications II: Human Body Joints Antifriction}

Human body joints are subjected to friction with coefficients of friction as low as $10^{-3}$ at pressures exceeding $10^{2} \mathrm{~atm}$, and they can maintain their lubrication for several decades. For this reason, they can be considered as models for the development of low-friction materials. Since human joints have a gel-like structure comprised of proteoglycans and collagen with high water content (75-80 $\mathrm{wt} \%$ ), gel lubricants can be ideal materials to reduce their tribological problems $[117,118]$. Gel fracture is mainly caused by stress concentration at the cross-linking point. Consequently, it is extremely important to design gels that can disperse stress, improving mechanical strength. For example, cyclodextrin and tetrapolyethylene glycol (PEG) are substances employed to reduce stress concentration [119,120]. Doublenetwork (DN) gels have structures with different polymer networks based on the fact that one polymer network prevents the fracture of the others [121]. Considering the fully explained beneficial properties of ILs, IL-type DN gels, also called DN ion gels, were recently proposed and studied for their low friction under high temperature and vacuum [122].

Clearly, in vitro and in vivo tests are necessary to reproduce accurate and reproducible measurements of human joint wear. In 2018, friction tests were conducted using a ball-on-plate type to simulate the human body joints and to study new DN ion gels as potential human lubricants. The authors [123] proposed and studied three new IL-type DN gels derived from poly 2-acrylamidomethyl-propanesulfonic acid (PAMPS), polydimethylacrylamide (PDAAm), and 3-ethyl-1-methyl-imidazolium ethylsulfate (EMI-EtSulf), in substitution of water. In particular, among other elements, they observed reduced friction with their DN ion gel with respect to a corresponding DN hydrogel (with water), probably due to an increased polymer adhesion caused by substituting water with the IL. Moreover, this increased lubrication regime may be also justified by the higher viscosity and thermal stability in comparison with DN hydrogels.

\section{Perspectives}

\subsection{Novel Approaches to Overcome the High Costs}

It must be pointed out that ILs are prepared by an often complex synthetic route, basically in two steps, involving the formation of the desired cation and the anion exchange 
(principally for metathesis or acid base neutralization) [124]. In particular, the metathesis process is used to prepare halide-free ILs in which the halide ion is exchanged with an anion of another chemical nature. Nevertheless, this reaction has some disadvantages such as the contamination with a small amount of residue halide ions that can generate collateral reactions with the metal surface, as discussed in Section 6.2. For this reason, as already mentioned in Section 5.1.2, halide-free direct synthesis represents a valid alternative to prepare ILs in an easy one-step reaction through the use of opportune starting reagents that allow the intermediate halide salt to be bypassed (for an example, see the typical procedure illustrated in [18]).

It is evident that the development of other innovative methodologies to form ILs can represent a valid strategy to prepare innovative and more highly performing ILs by easy and very cheap procedures. For example, it has been recently shown that they can be easily prepared at low cost by simply mixing two liquid amphiphiles: one with a basic character and the other with an acidic character. In such samples, the overall structure/property is the delicate equilibrium between the intermolecular association due to the $\mathrm{H}$-bonds and electrostatic forces of the charged molecules. In such structures, a marked nanosegregation of the apolar molecular moieties takes place. This nanosegregation is at the basis of many nonideal mixing behaviours [125] as well as other exotic properties (magnetically induced birefringence [126,127], anti-Arrhenian behaviour of conductivity [128]), which deserve to be monitored for value-added behaviour in specific applications. This, in our opinion, represents a simple and cheap strategy to prepare ILs and is followed, for example, by Calandra et al. [86] and by Vega et al. [109].

\subsection{Some Attention to Avoid the Possibility of Corrosion}

The chemical composition of employed ILs is crucial when dealing with corrosion problems. In fact, the use of ILs containing halogen (i.e., fluoride) can form metal halides as decomposition byproducts that may cause corrosion in steel [129,130], aluminium [131,132], bronze [133], and titanium [134] materials. To prevent damage due to the corrosion process and to avoid excessive reactions between halogen and metal, halogen-free ILs should be utilized, even if the boundary lubrication ability of halogen-free ILs can be slightly lower than those that contain halogen. For example, in 2017, Kawada and collaborators proposed a study on the lubrication of sliding materials, such as diamond-like carbon (DLC) and hydrogenfree diamond-like carbon (H-free DLC), that, recently, have been widely used as ecofriendly coatings with superior mechanical and tribological properties [135]. In particular, the lubricant activity of the halogen-free ionic liquids 1-butyl-3-methylimidazolium dicyanamide and 1-butyl-3-methylimidazolium tricyanomethane ([BMIM][DCN] and [BMIM][TCC], respectively, whose structures are reported in Figure 18, were tested on H-free DLC materials.

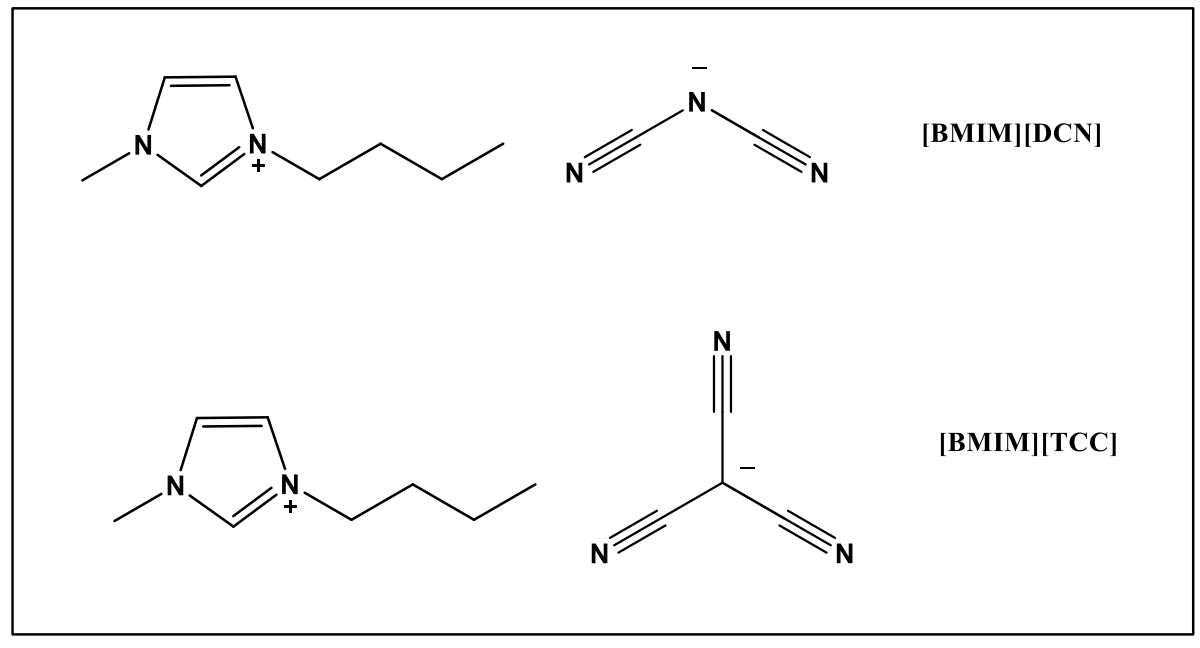

Figure 18. Chemical structure of $[\mathrm{BMIM}][\mathrm{DCN}]$ and $[\mathrm{BMIM}][\mathrm{TCC}]$. 
Accurate surface analyses by Raman spectroscopy, atomic force microscopy (AFM) and time-of-flight secondary ion mass spectrometry (TOF-SIMS) highlighted a superior protection activity of the tested contacting surfaces (i.e., a smoother surface and a lower friction) by using [BMIM][TCC] when compared with [BMIM][DCN]. The probable explanation of this phenomenon is due to the major adsorption of $\mathrm{CN}$ groups inside and outside the wear tracks of the tested surface, which for the [BMIM][TCC] is four times higher than the [BMIM][DCN]. The friction probably causes the thermal decomposition of [BMIM][TCC], generating isolated $\mathrm{CN}$ anions covering the $\mathrm{H}$-free-DLC surface.

In 2019, to overcome the wear and corrosion problems due the corrosive hydrogen fluoride formed by the degradation of the fluorinated ILs in the presence of water, an ionic liquid formed from a fluorinated phosphonium cation and a dicyanamide anion (tributyl-3,3,4,4,5,5,6,6,7,7,8,8,8-tridecafluorooctylphosphonium dicyanamide (see structure in Figure 19)) was studied at room temperature and at various levels of relative humidity [136].

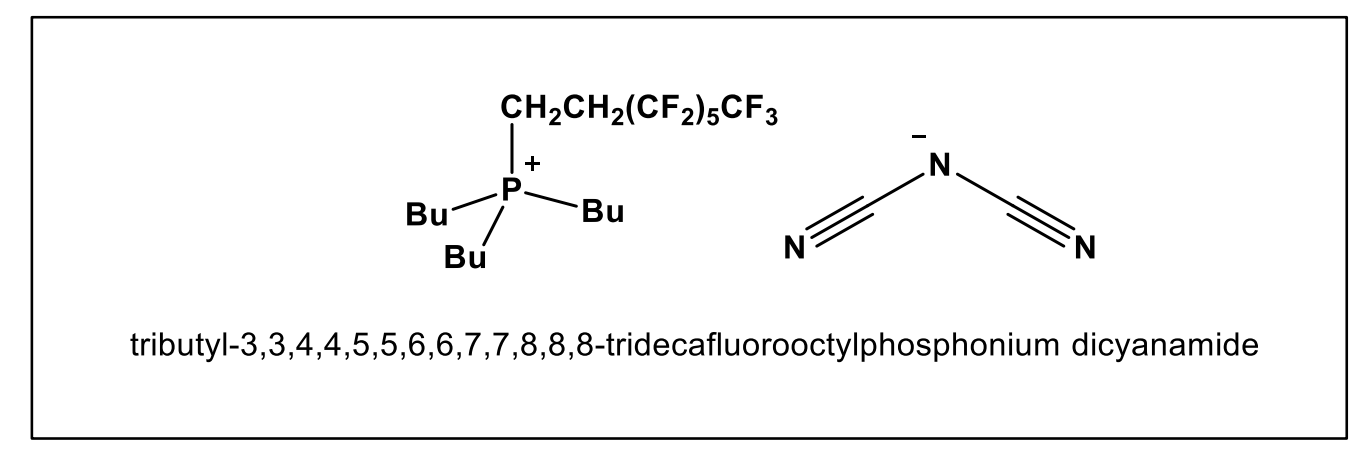

Figure 19. Chemical structure of the ionic liquid formed from a fluorinated phosphonium cation and a dicyanamide anion.

The results showed that the simultaneous presence of fluorine and phosphorus on the IL cation provided good lubricant properties conferred from the halogen presence and high corrosion-inhibiting properties due to the phosphonium group. To be clear, water was actually found to be a fundamental key to promoting the formation and growth of a tribolayer between steel contacts, because tests carried out in the presence of dry air showed a film limited only to the border of the contact area.

\subsection{Novel Structures}

The structure of an IL is inherently complex. This is due to the interplay of many different types of interactions of different strengths and occurring at different length scales. The coexistence of electrostatic interactions, typical of inorganic salts, based on the organic nature of the involved charged species provides all the good properties we have mentioned so far. In this regard, similar systems are made up of surfactants. Surfactants can, in fact, cause nanosegregation due to the separation of polar and apolar domains which are made by the polar (head) and apolar (tails) moieties of each single molecule, opportunely organized to form local assemblies. Additionally, in this case, liquid state, long range structure, and high viscosity are usually present, depending, however, on the specific substance. This aspect makes it clear that liquid amphiphiles somehow share the structural features of ILs, as already usefully pointed out in 2010 [137]. For example, alkylphosphates are characterized by a prepeak (peak at lower q values) in the wide-angle X-ray scattering spectrum, whereas octanoic acids and alkylamine are not.

In this framework, to enrich the scenario of the possible interactions existent in the system, ILs can be mixed with liquid surfactants. In this situation, the number and types of interactions would be increased, allowing, in principle, higher configurational possibilities and interesting resulting systems. Interesting mixing behaviour [138] and mixed structures [139] have been observed, which overall foster strong synergistic interactions. The complex behaviour of such systems can cause new and somehow unexpected emerging 
properties to arise [140]. However, generally speaking, we notice that there is a peculiar effect given by the fact that the positive-negative (charge) separation typical of ionic liquids competes with the polar-apolar (polarity) separation of the neat surfactant. Additionally, competition between different driving forces is at the basis of smart materials, since the overall structure/dynamics (briefly, the behaviour) of a system can be influenced by an external stimulus [141] with great repercussions in many scientific and technological fields [142].

\subsection{IL-Metals}

In our opinion, ILs containing metal ions or metal nanoparticles show promising features for obtaining conductive lubricants to be used in sliding electrical contacts, a research area still not explored enough. Lithium ILs were used to obtain conductive lubricant greases [143]. ILs doped with copper nanowires that generated metal ions in time were used to improve the tribology property and conductivity in lubricating greases [144]. Additionally, copper and silver nanoparticles as lubricant additives in different ILs were tested under applied electric currents and a reduction of electro corrosion and the enhancement of rolling effects of particles in the contact region were observed [145]. ILs doped with copper oxide nanorods or zinc oxide nanoparticles were showed to exhibit excellent friction and wear reduction [146-148]. Given this background, there is still much research to be done for optimizing the lubricant properties in order to benefit from both the IL properties and electronic properties of the metal centre.

\subsection{Commercialization}

After accurate evaluation, we may surely coin for ILs the term futurekind to highlight the wide range of their applications, starting from the substitution of the classical reaction solvent to their use in industrial processes [149]. In fact, the latter often suffer from the hazardous problems of toxicity, flammability, and the decomposition in systems at high temperatures or pression surely due to the chemical nature of the solvents and reagents used, but also due to the large amount of employed starting materials. Therefore, the development of more innovative industrial procedures is crucial through the use, for example, of less hazardous chemicals to permit safety in production plants and to protect the environment [150]. As already mentioned, ILs can be considered as green solvents for their capacity for recycling without loss of activity, negligible vapour pressure, nonflammability, and high thermostability and may be represented as a valid alternative to dangerous solvents [151].

Therefore, the idea to substitute common solvents with ILs is certainly of great interest, enough to recently establish close cooperation between the academic and industrial communities with the purpose of producing a wide diversity of ILs [152]. This aspect puts the focus on a very significant perspective: how important is the more extensive commercialization of ionic liquids for easily accessing a variety of ILs with different cations, anions, and properties?

In our opinion, this is one of the most crucial aspects that should overcome the limited access to a multiplicity and tuneability of ILs depending on their use. In fact, the presence in the literature of many research papers and patents does yet not assure a plethora of production processes of ILs on a commercial scale [153]. Surely, ionic liquids are more expensive than conventional solvents or additives, but their initial capital cost does not have to confine them only to applications as reaction solvents or catalysts. In fact, their benefits may orient their commercialisation towards, for example, applications of high electrochemical and thermal stabilities/conductivities, as high-performance additives, as analytical materials, or for other, probably more fascinating, unpredictable applications [154].

Author Contributions: P.C. methodology, conceptualization, writing; E.I.S. conceptualization, methodology; D.L. supervision, conceptualization; V.A. methodology, conceptualization; A.D.N. investigation; L.M. investigation, writing. All authors have read and agreed to the published version of the manuscript. 
Funding: This research received no external funding.

Institutional Review Board Statement: Not applicable.

Acknowledgments: E.I.S. acknowledges the Romanian Academy, Program 4. Financial support from the CNR-RA Romania bilateral project 2020-2022 (proposal n. 4657/2019) is acknowledged. This permitted fruitful discussions. The University of Calabria and Calabria Region (PAC CALABRIA 2014-2020-Asse Prioritario 12, Azione B 10.5.12 CUP: H28D19000040006) are acknowledged for financial support.

Conflicts of Interest: The authors declare no conflict of interest.

\section{References}

1. Bowden, F.P.; Tabor, D. The Friction and Lubrication of Solids; Oxford University Press: Oxford, UK, 1950; pp. 1-337.

2. Kardar, M.; Golestanian, R. The "friction" of vacuum, and other fluctuation-induced forces. Rev. Mod. Phys. 1999, 71, 1233-1245. [CrossRef]

3. Lhermerout, R.; Diederichs, C.; Perkin, S. Are Ionic Liquids Good Boundary Lubricants? A Molecular Perspective. Lubricants 2018, 6, 9. [CrossRef]

4. Ye, C.F.; Liu, W.M.; Chen, Y.X.; Yu, L.G. Room-temperature ionic liquids: A novel versatile lubricant. Chem. Commun. 2001, 2244-2245. [CrossRef]

5. Earle, M.J.; Seddon, K.R. Ionic liquids. Green solvents for the future. Pure Appl. Chem. 2000, 72, 1391-1398. [CrossRef]

6. Somers, A.E.; Howlett, P.C.; MacFarlane, D.R.; Forsyth, M.A. Review of Ionic Liquid Lubricants. Lubricants $2013,1,3-21$. [CrossRef]

7. Bhushan, B.; Palacio, M.; Kinzig, B. AFM-Based Nanotribological and Electrical Characterization of Ultrathin Wear-Resistant Ionic Liquid Films. J. Colloid Interface Sci. 2008, 317, 275-287. [CrossRef]

8. Goossens, K.; Lava, K.; Bielawski, C.W.; Binnemans, K. Ionic Liquid Crystals: Versatile Materials. Chem. Rev. 2016, 116, $4643-4807$. [CrossRef]

9. Calandra, P.; Caponetti, E.; Martino, D.C.; D'Angelo, P.; Minore, A.; Turco Liveri, V. FT-IR and Dielectric study of water/AOT liquid crystals. J. Mol. Struct. 2000, 522, 165-178. [CrossRef]

10. Donato, M.T.; Colaço, R.; Branc, L.C.; Saramago, B. A review on alternative lubricants: Ionic liquids as additives and deep eutectic solvents. J. Mol. Liq. 2021, 333, 116004-116029. [CrossRef]

11. Li, Z.; Mangolini, F. Recent Advances in Nanotribology of Ionic Liquids. Exp. Mech. 2021. [CrossRef]

12. Xiao, H. Ionic Liquid Lubricants: Basics and Applications. Tribol. Trans. 2017, 60, 20-30. [CrossRef]

13. Bermúdez, M.-D.; Jiménez, A.-E.; Sanes, J.; Carrión, F.-J. Ionic Liquids as Advanced Lubricant Fluids. Molecules 2009, 14, 2888-2908. [CrossRef]

14. Amiri, S.A.S.; Rahim, E.A.; Syahrullail, S. A review on ionic liquids as sustainable lubricants in manufacturing and engineering: Recent research, performance, and application. J. Clean. Prod. 2017, 168, 1571-1589. [CrossRef]

15. Kondo, Y.; Koyama, T.; Sasaki, S. Tribological Properties of Ionic Liquids in Ionic Liquids-New Aspects for the Future. IntechOpen 2013, 5, 127-141.

16. Perkin, S.; Albrecht, T.; Klein, J. Layering and shear properties of an ionic liquid, 1-ethyl-3-methylimidazolium ethylsulfate, confined to nano-films between mica surfaces. Phys. Chem. Chem. Phys. 2010, 12, 1243-1247. [CrossRef] [PubMed]

17. Wang, T.-H.; Hsu, L.-W.; Chang, H.-C. Structural Reorganization of Imidazolium Ionic Liquids Induced by Pressure-Enhanced Ionic Liquid-Polyethylene Oxide Interactions. Int. J. Mol. Sci. 2021, 22, 981. [CrossRef]

18. Chang, H.-C.; Wang, T.-H.; Burba, C.M. Probing Structures of Interfacial 1-Butyl-3-Methylimidazolium Trifluoromethanesulfonate Ionic Liquid on Nano-Aluminum Oxide Surfaces Using High-Pressure Infrared Spectroscopy. Appl. Sci. 2017, 7, 855. [CrossRef]

19. Han, M.; Espinosa-Marzal, R.M. Molecular Mechanisms Underlying Lubrication by Ionic Liquids: Activated Slip and Flow. Lubricants 2018, 6, 64. [CrossRef]

20. Li, H.; Cooper, P.K.; Somers, A.E.; Rutland, M.W.; Howlett, P.C.; Forsyth, M.; Atkin, R. Ionic Liquid Adsorption and Nanotribology at the Silica-Oil Interface: Hundred-Fold Dilution in Oil Lubricates as Effectively as the Pure Ionic Liquid. J. Phys. Chem. Lett. 2014, 5, 4095-4099. [CrossRef]

21. Welton, T. Ionic liquids: A brief history. Biophys. Rev. 2018, 10, 691-706. [CrossRef]

22. Maiuolo, L.; Algieri, V.; Olivito, F.; De Nino, A. Recent Developments on 1,3-Dipolar Cycloaddition Reactions by Catalysis in Green Solvents. Catalysts 2020, 10, 65. [CrossRef]

23. Welton, T. Room-Temperature Ionic Liquids. Solvents for Synthesis and Catalysis. Chem. Rev. 1999, 99, 2071-2084. [CrossRef] [PubMed]

24. De Nino, A.; Merino, P.; Algieri, V.; Nardi, M.; Di Gioia, M.L.; Russo, B.; Tallarida, M.A.; Maiuolo, L. Synthesis of 1,5-Functionalized 1,2,3-Triazoles Using Ionic Liquid/Iron (III) Chloride as an Efficient and Reusable Homogeneous Catalyst. Catalysts 2018, 8 , $364-376$.

25. Hallett, J.P.; Welton, T. Room-Temperature Ionic Liquids: Solvents for Synthesis and Catalysis 2. Chem. Rev. 2011, 111, 3508-3576. [CrossRef] 
26. De Nino, A.; Algieri, V.; Tallarida, M.A.; Costanzo, P.; Pedrón, M.; Tejero, T.; Merino, P.; Maiuolo, L. Regioselective Synthesis of 1,4,5-Trisubstituted-1,2,3-Triazoles from Aryl Azides and Enaminones. Eur. J. Org. Chem. 2019, 33, 5725-5731. [CrossRef]

27. De Nino, A.; Maiuolo, L.; Merino, P.; Nardi, M.; Procopio, A.; Roca-Lopez, D.; Russo, B.; Algieri, V. Efficient Organocatalyst Supported on a Simple Ionic Liquid as a Recoverable System for the Asymmetric Diels-Alder Reaction in the Presence of Water. ChemCatChem 2015, 7, 830-835. [CrossRef]

28. Mu, Z.; Zhou, F.; Zhang, S.; Liang, Y.; Liu, W. Effect of the Functional Groups in Ionic Liquid Molecules on the Friction and Wear Behavior of Aluminum Alloy in Lubricated Aluminum-on Steel Contact. Tribol. Int. 2005, 38, 725-731. [CrossRef]

29. Itoh, T.; Watanabe, N.; Inada, K.; Ishioka, A.; Hayase, S.; Kawatsura, M.; Minami, I.; Mori, S. Design of Alkanesulfonate Ionic Liquids for Lubricants. Chem. Lett. 2009, 38, 64-65. [CrossRef]

30. Zhou, F.; Liang, Y.; Liu, W. Ionic Liquid Lubricants: Designed Chemistry for Engineering Applications. Chem. Soc. Rev. 2009, 38, 2590-2599. [CrossRef]

31. Xie, G.; Luo, J.; Guo, D.; Liu, S. Nanoconfined Ionic Liquids under Electric Fields. Appl. Phys. Lett. 2010, 96, 043112. [CrossRef]

32. Hansen, J.-P.; McDonald, I.R. Theory of Simple Liquids with Applications to Soft Matter, 4th ed.; Academic Press: Cambridge, MA, USA, 2013; pp. 1-619.

33. Triolo, A.; Russina, O.; Bleif, H.-J.; Di Cola, E. Nanoscale Segregation in Room Temperature Ionic Liquids. J. Phys. Chem. B 2007, 111, 4641-4644. [CrossRef]

34. Triolo, A.; Russina, O.; Fazio, B.; Appetecchi, G.B.; Carewska, M.; Passerini, S. Nanoscale organization in piperidinium-based room temperature ionic liquids. J. Chem. Phys. 2009, 130, 164521. [CrossRef] [PubMed]

35. Triolo, A.; Russina, O.; Fazio, B.; Triolo, R.; Di Cola, E. Morphology of 1-alkyl-3-methylimidazolium hexafluorophosphate room temperature ionic liquids Chem. Phys. Lett. 2008, 457, 362-365.

36. Canongia Lopes, J.N.; Costa Gomes, M.F.; Pádua, A.A.H. Nonpolar, Polar, and Associating Solutes in Ionic Liquids. J. Phys. Chem. B 2006, 110, 16816-16818. [CrossRef]

37. Granick, S. Motions and Relaxations of Confined Liquids. Science 1991, 253, 1374-1379. [CrossRef] [PubMed]

38. Zaera, F. Probing Liquid/Solid Interfaces at the Molecular Level. Chem. Rev. 2012, 112, 2920-2986. [CrossRef]

39. Bain, C.D. Sum-frequency vibrational spectroscopy of the solid/liquid interface. J. Chem. Soc. Faraday Trans. 1995, 91, 1281-1296. [CrossRef]

40. Voïtchovsky, K. Anharmonicity, solvation forces, and resolution in atomic force microscopy at the solid-liquid interface. Phys. Rev. E 2013, 88, 022407. [CrossRef]

41. Voïtchovsky, K.; Kuna, J.J.; Contera, S.A.; Tosatti, E.; Stellacci, F. Direct mapping of the solid-liquid adhesion energy with sub-nanometre resolution. Nat. Nanotechnol. 2010, 5, 401-405. [CrossRef]

42. Kuna, J.J.; Voïtchovsky, K.; Singh, C.; Jiang, H.; Mwenifumbo, S.; Ghorai, P.K.; Stevens, M.M.; Glotzer, S.C.; Stellacci, F. The effect of nanometre-scale structure on interfacial energy. Nat. Mater. 2009, 8, 837-842. [CrossRef] [PubMed]

43. Ricci, M.; Spijker, P.; Voïtchovsky, K. Water-induced correlation between single ions imaged at the solid-liquid interface. Nat. Commun. 2014, 5, 4400. [CrossRef]

44. Gómez-Márquez, J. What are the principles that govern life? Commun. Integr. Biol. 2020, 13, 97-107. [CrossRef] [PubMed]

45. Hayes, R.; Warr, G.G.; Atkin, R. Structure and Nanostructure in Ionic Liquids. Chem. Rev. 2015, 115, 6357-6426. [CrossRef] [PubMed]

46. Hayes, R.; Wakeham, D.; Atkin, R. Interfaces of Ionic Liquids in Ionic Liquids UnCOILed: Critical Expert Overviews; Seddon, K.R., Plechkova, N., Eds.; John Wiley \& Sons: New York, NY, USA, 2012; pp. 51-86.

47. Atkin, R.; El Abedin, S.Z.; Hayes, R.; Gasparotto, L.H.S.; Borisenko, N.; Endres, F. AFM and STM Studies on the Surface Interaction of [BMP]TFSA and [EMIm]TFSA Ionic Liquids with Au(111) F. J. Phys. Chem. C 2009, 113, 13266-13272. [CrossRef]

48. Hayes, R.; El Abedin, S.Z.; Atkin, R. Pronounced Structure in Confined Aprotic Room-Temperature Ionic Liquids. J. Phys. Chem. B 2009, 113, 7049-7052. [CrossRef] [PubMed]

49. Wakeham, D.; Hayes, R.; Warr, G.G.; Atkin, R. Influence of Temperature and Molecular Structure on Ionic Liquid Solvation Layers. J. Phys. Chem. B 2009, 113, 5961-5966. [CrossRef] [PubMed]

50. Horn, R.G.; Evans, D.F.; Ninham, B.W. Double-layer and solvation forces measured in a molten salt and its mixtures with water. J. Phys. Chem. 1988, 92, 3531-3537. [CrossRef]

51. Israelachvili, J.N. Intermolecular and Surface Forces, 3rd ed.; Elsevier: London, UK, 2011; pp. 1-704.

52. Lim, R.; O'Shea, S. Solvation Forces in Branched Molecular Liquids. J. Phys. Rev. Lett. 2002, 88, 246101. [CrossRef] [PubMed]

53. Israelachvili, J. Solvation forces and liquid structure, as probed by direct force measurements. Acc. Chem. Res. 1987, 20, 415-421. [CrossRef]

54. Meusel, M.; Lexow, M.; Gezmis, A.; Schötz, S.; Wagner, M.; Bayer, A.; Maier, F. Steinrück H-P. Atomic Force and Scanning Tunneling Microscopy of Ordered Ionic Liquid Wetting Layers from $110 \mathrm{~K}$ up to Room Temperature. ACS Nano 2020, 14, 9000-9010. [CrossRef] [PubMed]

55. Graves, A.D. The electrical double layer in molten salts: Part 1-The potential of zero charge. Electroanal. Chem. 1970, 25, 349-356. [CrossRef]

56. Graves, A.D. The electrical double layer in molten salts: Part 2-The double-layer capacitance. Electroanal. Chem. 1970, 25, 357-372. [CrossRef] 
57. Heyes, D.M.; Clarke, J.H. Computer simulation of molten-salt interphases-Effect of a rigid boundary and an applied electric field. J. Chem. Soc. Faraday Trans. 2 1981, 77, 1089-1100. [CrossRef]

58. Atkin, R.; Craig, V.S.J.; Wanless, E.J.; Biggs, S. Mechanism of cationic surfactant adsorption at the solid-aqueous interface. Adv. Colloid Interface Sci. 2003, 103, 219-304. [CrossRef]

59. Warr, G.G. Surfactant adsorbed layer structure at solid/solution interfaces: Impact and implications of AFM imaging studies. Curr. Opin. Colloid Interface Sci. 2000, 5, 88-94. [CrossRef]

60. Halling, J. Hydrodynamic Lubrication. In Principles of Tribology; Palgrave: London, UK, 1978.

61. Koyama, T.; Tsuboi, R.; Sasaki, S. Research on lubricity of ionic liquid for metal alloys. In Proceedings of the JAST Tribology Conference, Tokyo, Japan, 30 October-3 November 2011; pp. 47-48.

62. Avilés, M.D.; Pamies, R.; Sanes, J.; Carrión, F.J.; Bermúdez, M.D. Fatty acid-derived ionic liquid lubricant: Protic ionic liquid additives. Coatings 2019, 9, 710. [CrossRef]

63. Avilés, M.D.; Pamies, R.; Sanes, J.; Arias-Pardilla, J.; Carrión, F.J.; Bermúdez, M.D. Protic ammonium bio-based ionic liquid crystal lubricants. Tribol. Int. 2021, 158, 106917-106925. [CrossRef]

64. Mia, S.; Tomozawa, K.; Morita, S.; Ohno, N. High-pressure rheology of ionic liquid. In Proceedings of the World Tribology Congress IV, Kyoto, Japan, 6-11 September 2009; p. 572.

65. Rosenblum, B.; Brauelich, P.; Mimmel, L. Spontaneous emission of charged particles and photons during tensile deformation of oxide-covered metals under ultrahigh-vacuum conditions, J. Appl. Phys. 1977, 48, 5262-5273. [CrossRef]

66. Kajdas, C. Importance of Anionic Reactive Intermediates for Lubricant Component Reactions with Friction Surfaces. Lubr. Sci. 1994, 6, 203-228. [CrossRef]

67. Elbourne, A.; Sweeney, J.; Webber, G.B.; Wanless, E.J.; Warr, G.G.; Rutland, M.W.; Atkin, R. Adsorbed and near-surface structure of ionic liquids determines nanoscale friction. Chem. Commun. 2013, 49, 6797-6799. [CrossRef]

68. Yanga, S.; Wong, J.S.S.; Zhoub, F. Ionic Liquid Additives for Mixed and Elastohydrodynamic Lubrication. Tribol. Trans. 2018, 61, 816-826. [CrossRef]

69. Li, Q. Functional Organic and Hybrid Nanostructured Materials: Fabrication, Properties, and Applications; Wiley-VCH Verlag GmbH \& Co. KGaA: Weinheim, Germany, 2018; pp. 1-638.

70. Bonaccorsi, L.; Calandra, P.; Amenitsch, H.; Proverbio, E.; Lombardo, D. Growth of fractal aggregates during template directed SAPO-34 zeolite formation. Microporous Mesoporous Mater. 2013, 167, 3-9. [CrossRef]

71. Chen, C.; Wylie, R.A.L.; Klinger, D.; Connal, L.A. Shape Control of Soft Nanoparticles and Their Assemblies. Chem. Mater. 2017, 29, 1918-1945. [CrossRef]

72. Lombardo, D.; Calandra, P.; Magazù, S.; Wanderlingh, U.; Barreca, D. Soft nanoparticles charge expression within lipid membranes: The case of amino terminated dendrimers in bilayers vesicles. Colloids Surf. B Biointerfaces 2018, 170, 609-616. [CrossRef]

73. Lombardo, D.; Munaò, G.; Calandra, P.; Pasqua, L.; Caccamo, M.T. Evidence of pre-micellar aggregates in aqueous solution of amphiphilic PDMS-PEO block copolymer. Phys. Chem. Chem. Phys. 2019, 21, 11983-11991. [CrossRef] [PubMed]

74. Lombardo, D.; Calandra, P.; Caccamo, M.T.; Magazu, S.; Kiselev, M.A. Colloidal stability of liposomes. AIMS Mater. Sci. 2019, 6, 200-213. [CrossRef]

75. Lombardo, D.; Calandra, P.; Kiselev, M.A. Structural Characterization of Biomaterials by Means of Small Angle X-rays and Neutron Scattering (SAXS and SANS), and Light Scattering Experiments. Molecules 2020, 25, 5624. [CrossRef] [PubMed]

76. Zemb, T.; Lindner, P. Neutron, X-rays and Light Scattering Methods Applied to Soft Condensed Matter; North-Holland Elsevier: Amsterdam, The Netherlands, 2002.

77. Kiselev, M.A.; Lombardo, D. Structural characterization in mixed lipid membrane systems by neutron and X-ray scattering. Biochim. Biophys. Acta 2017, 1861, 3700-3717. [CrossRef]

78. Bonaccorsi, L.; Calandra, P.; Kiselev, M.A.; Amenitsch, H.; Proverbio, E.; Lombardo, D. Self-assembly in poly(dimethylsiloxane)poly(ethylene oxide) block copolymer template directed synthesis of linde type A zeolite. Langmuir 2013, 29, 7079-7086. [CrossRef] [PubMed]

79. Nagana Gowda, G.A.; Chen, H.; Khetrapal, C.L.; Weiss, R.G. Amphotropic Ionic Liquid Crystals with Low Order Parameters. Chem. Mater. 2004, 16, 2101-2106. [CrossRef]

80. Tomšič, M.; Jamnik, A.; Fritz-Popovski, G.; Glatter, O.; Vlček, L. Structural Properties of Pure Simple Alcohols from Ethanol, Propanol, Butanol, Pentanol, to Hexanol: Comparing Monte Carlo Simulations with Experimental SAXS Data. J. Phys. Chem. B 2007, 111, 1738-1751. [CrossRef]

81. Mariani, A.; Ballirano, P.; Angiolari, F.; Caminiti, R.; Gontrani, L. Does High Pressure Induce Structural Reorganization in Linear Alcohols? A Computational Answer. ChemPhysChem 2016, 17, 3023-3029. [CrossRef]

82. Calandra, P.; Ruggirello, A.; Mele, A.; Liveri, V.T. Self-assembly in surfactant-based liquid mixtures: Bis(2-ethylhexyl)phosphoric acid/bis(2-ethylhexyl)amine systems. J. Colloid Interface Sci. 2010, 348, 183-188. [CrossRef] [PubMed]

83. Calandra, P.; Turco Liveri, V.; Riello, P.; Freris, I.; Mandanici, A. Self-assembly in surfactant-based liquid mixtures: Octanoic acid/Bis(2-ethylhexyl)amine systems. J. Colloid Interface Sci. 2012, 367, 280-285. [CrossRef]

84. Calandra, P.; Mandanici, A.; Turco Liveri, V. Self-assembly in surfactant-based mixtures driven by acid-base reactions: Bis(2ethylhexyl) phosphoric acid-n-octylamine systems. RSC Adv. 2013, 3, 5148. [CrossRef] 
85. Mariani, A.; Caminiti, R.; Campetella, M.; Gontrani, L. Pressure-induced mesoscopic disorder in protic ionic liquids: First computational study Phys. Chem. Chem. Phys. 2016, 18, 2297-2302. [CrossRef] [PubMed]

86. Atkin, R.; Warr, G.G. The Smallest Amphiphiles: Nanostructure in Protic Room-Temperature Ionic Liquids with Short Alkyl Groups. J. Chem. Phys. B Lett. 2008, 112, 4164-4166. [CrossRef] [PubMed]

87. Russina, O.; Sferrazza, A.; Caminiti, R.; Triolo, A. Amphiphile Meets Amphiphile: Beyond the Polar-Apolar Dualism in Ionic Liquid/Alcohol Mixtures. J. Phys. Chem. Lett. 2014, 5, 1738-1742. [CrossRef] [PubMed]

88. Turco Liveri, V.; Lombardo, D.; Pochylski, M.; Calandra, P. Molecular association of small amphiphiles: Origin of ionic liquid properties in dibutyl phosphate/propylamine binary mixtures. J. Mol. Liq. 2018, 263, 274-281. [CrossRef]

89. Castner, E.W.; Wishart, J.F. Spotlight on ionic liquids J. Chem. Phys. 2010, 132, 120901. [CrossRef]

90. Hayes, R.; Imberti, S.; Warr, G.G.; Atkin, R. Pronounced sponge-like nanostructure in propylammonium nitrate. Phys. Chem. Chem. Phys. 2011, 13, 13544-13551. [CrossRef] [PubMed]

91. Ricci, M.; Spijker, P.; Stellacci, F.; Molinari, J.-F.; Voïtchovsky, K. Direct visualization of single ions in the Stern layer of calcite. Langmuir 2013, 29, 2207-2216. [CrossRef] [PubMed]

92. Elbourne, A.; Voitchovsky, K.; Warr, G.; Atkin, R. Ion structure controls ionic liquid near-surface and interfacial nanostructure. Chem. Sci. 2015, 6, 527-536. [CrossRef] [PubMed]

93. Segura, J.J.; Elbourne, A.; Wanless, E.J.; Warr, G.G.; Voïtchovsky, K.; Atkin, R. Adsorbed and near surface structure of ionic liquids at a solid interface. Phys. Chem. Chem. Phys. 2013, 15, 3320. [CrossRef] [PubMed]

94. Seddon, J.R.T. Conservative and Dissipative Interactions of Ionic Liquids in Nanoconfinement. J. Phys. Chem. C 2014, 118, 22197-22201. [CrossRef]

95. Chen, C.J. Introduction to Scanning Tunnelling Microscopy; Oxford University Press: New York, NY, USA, $1993 ;$ pp. 1-488.

96. Muller, E.A.; Strader, M.L.; Johns, J.E.; Yang, A.; Caplins, B.W.; Shearer, A.J.; Suich, D.E.; Harris, C.B. Femtosecond Electron Solvation at the Ionic Liquid/Metal Electrode Interface. J. Am. Chem. Soc. 2013, 135, 10646-10653. [CrossRef]

97. Aliaga, C.; Baldelli, S. A Sum Frequency Generation Study of the Room-Temperature Ionic Liquid-Titanium Dioxide Interface. J. Phys. Chem. C 2008, 112, 3064-3072. [CrossRef]

98. Mariani, A.; Bonomo, M.; Wu, B.; Centrella, B.; Dini, D.; Castner, E.W., Jr.; Gontrani, L. Intriguing transport dynamics of ethylammonium nitrate-acetonitrile binary mixtures arising from nano-inhomogeneity. Phys. Chem. Chem. Phys. 2017, 19, 27212-27220. [CrossRef]

99. Seddon, K.R.; Stark, A.; Torres, M.-J. Influence of chloride, water, and organic solvents on the physical properties of ionic liquids. Appl. Chem. 2000, 72, 2275-2287. [CrossRef]

100. Lawes, S.D.A.; Hainsworth, S.V.; Blake, P.; Ryder, K.S.; Abbott, A.P. Lubrication of Steel/Steel Contacts by Choline Chloride Ionic Liquids. Tribol. Lett. 2010, 37, 103-110. [CrossRef]

101. Zhu, L.-Y.; Chen, L.-G.; Yang, X.; Song, H.-B. Functionalized Ionic Liquids as Lubricants for Steel-Steel Contact. Appl. Mech. Mater. 2012, 138, 630-634. [CrossRef]

102. García, A.; González, R.; HernándezBattez, A.; Viesca, J.L.; Monge, R.; Fernández-González, A.M. Hadfield Ionic liquids as a neat lubricant applied to steel-steel contacts. Tribol. Int. 2014, 72, 42-50. [CrossRef]

103. Matweb. Solvay Specialty Polymers Fomblin®Z25 PFPE Lubricant. Available online: http://www.matweb.com/search/ datasheet_print.aspx?matguid=0fe558c6e3c941f5b7a4168fa2d26fee (accessed on 12 April 2019).

104. Dörr, N.; Merstallinger, A.; Holzbauer, R.; Pejaković, V.; Brenner, J.; Pisarova, L.; Stelzl, J.; Frauscher, M. Five-Stage Selection Procedure of Ionic Liquids for Lubrication of Steel-Steel Contacts in Space Mechanisms. Tribol. Lett. 2019, 67, 1-18. [CrossRef]

105. Nie, L.R.; Song, H.; Yohannes, A.; Liang, S.W.; Yao, S. Extraction in cholinium-based magnetic ionic liquid aqueous two-phase system for the determination of berberine hydrochloride in Rhizomacoptidis. RSC Adv. 2018, 8, 44-25201. [CrossRef]

106. Jia, J.; Yang, G.; Zhang, C.; Zhang, S.; Zhang, Y.; Zhang, P. Effects of magnetic ionic liquid as a lubricant on the friction andwear behavior of a steel-steel sliding contact under elevated temperatures. Friction 2021, 9, 61-74. [CrossRef]

107. Singh, K.K.; Singh, S.; Shrivastava, A.K. Study of Tribological Behavior of Silicon Carbide Based Aluminum Metal Matrix Composites under Dry and Lubricated Environment. Adv. Mater. Sci. Eng. 2016, 2016, 3813412-3813422. [CrossRef]

108. Espinosa, T.; Sanes, J.; Jiménez, A.E.; Bermúdez, M.D. Protic ammonium carboxylate ionic liquid lubricants of OFHC copper. Wear 2013, 303, 495-509. [CrossRef]

109. Ortega Vega, M.R.; Parise, K.; Ramos, L.B.; Boff, U.; Mattedi, S.; Schaeffer, L.; Malfatti, C.F. Protic Ionic Liquids Used as Metal-Forming Green Lubricants for Aluminum: Effect of Anion Chain Length. Mater. Res. 2017, 20, 675-687. [CrossRef]

110. Zhang, H.-b.; Chen, H.; Shi, X.-n.; Liu, X.; Duan, G.-j. Tribological properties of ionic liquids for steel/aluminum, steel/copper and steel $/ \mathrm{Si}_{3} \mathrm{~N}_{4}$ ceramic contacts under boundary lubrication. Ind. Lubr. Tribol. 2018, 70, 1158-1168. [CrossRef]

111. Patel, A.; Guo, H.; Iglesias, P. Study of the Lubricating Ability of Protic Ionic Liquid on an Aluminum-Steel Contact. Lubricants 2018, 6, 66. [CrossRef]

112. An, R.; Zhu, Y.; Wu, N.; Xie, W.; Lu, J.; Feng, X.; Lu, X. Wetting Behavior of Ionic Liquid on Mesoporous Titanium Dioxide Surface by Atomic Force Microscopy. ACS Appl. Mater. Interfaces 2013, 5, 2692-2698. [CrossRef]

113. Li, H.; Somers, A.E.; Rutland, M.W.; Howlett, P.C.; Atkin, R. Combined Nano- and Macrotribology Studies of Titania Lubrication Using the Oil-Ionic Liquid Mixtures. ACS Sustain. Chem. Eng. 2016, 4, 5005-5012. [CrossRef]

114. Cooper, P.K.; Staddon, J.; Zhang, S.; Aman, Z.M.; Atkin, R.; Li, H. Nano- and Macroscale Study of the Lubrication of Titania Using Pure and Diluted Ionic Liquids. Front. Chem. 2019, 7, 287-295. [CrossRef] [PubMed] 
115. Kondo, H. Tribochemistry of Ionic Liquid Lubricant on Magnetic Media. Adv. Tribol. 2012, 1-20. [CrossRef]

116. Kondo, H. Ionic Liquid Lubricant with Ammonium Salts for Magnetic Media in Applications of Ionic Liquids in Science and Technology; InTech Publisher: London, UK, 2011; pp. 1-516.

117. Gong, J.P.; Kurokawa, T.; Narita, T.; Kagata, G.; Osada, Y.; Nishimura, G.; Kinjo, M. Synthesis of hydrogels with extremely low surface friction. J. Am. Chem. Soc. 2001, 123, 5582-5583. [CrossRef] [PubMed]

118. Ren, H.-Y.; Mizukami, M.; Tanabe, T.; Furukawa, H.; Kurihara, K. Friction of polymer hydrogels studied by resonance shear measurements. Soft Matter 2015, 11, 6192-6200. [CrossRef]

119. Okumura, Y.; Ito, K. The polyrotaxane gels: A topological gel by figure-of eight cross-links. Adv. Mater. 2001, 13, 485-487. [CrossRef]

120. Sakai, T.; Matsunaga, T.; Yamamoto, Y.; Ito, C.; Yoshida, R.; Suzuki, S.; Sasaki, N.; Shibayama, M.; Chung, U. Design and Fabrication of a High-Strength Hydrogel with Ideally Homogeneous Network Structure from Tetrahedron-like Macromonomers. Macromolecules 2008, 41, 5379-5384. [CrossRef]

121. Gong, J.P.; Katsuyama, Y.; Kurokawa, T.; Osada, Y. Double-Network Hydrogels with Extremely High Mechanical Strength. Adv. Mater. 2003, 15, 1155-1158. [CrossRef]

122. Arafune, H.; Honma, S.; Morinaga, T.; Kamijo, T.; Miura, M.; Furukawa, H.; Sato, T. Highly Robust and Low Frictional Double-Network Ion Gel. Adv. Mater. Interfaces 2017, 4, 1700074-1700078. [CrossRef]

123. Arafune, H.; Muto, F.; Kamijo, T.; Honma, S.; Morinaga, T.; Sato, T. Tribological Properties of Double-Network Gels Substituted by Ionic Liquids. Lubricants 2018, 6, 89. [CrossRef]

124. Ratti, R. Ionic Liquids: Synthesis and Applications in Catalysis Advances in Chemistry Adv. Chem. 2014, 729842. [CrossRef]

125. Calandra, P.; Turco Liveri, V.; Proietti, N.; Capitani, D.; Lombardo, D.; Gainaru, C.; Böhmer, R.; Kozak, M.; Dobies, M.; Fojud, Z.; et al. Non-ideal mixing behavior in dibutyl phosphate-propylamine binary liquids: Dielectric and nuclear magnetic resonance investigations. J. Mol. Liq. 2021, 323, 114963. [CrossRef]

126. Calandra, P. On the physico-chemical basis of self-nanosegregation giving magnetically-induced birefringence in dibutyl phosphate/bis(2-ethylhexyl) amine systems. J. Mol. Liq. 2020, 310, 113186. [CrossRef]

127. Pochylski, M.; Lombardo, D.; Calandra, P. Optical Birefringence Growth Driven by Magnetic Field in Liquids: The Case of Dibutyl Phosphate/Propylamine System. Appl. Sci. 2020, 10, 164. [CrossRef]

128. Calandra, P.; Turco Liveri, P.; Ruggirello, A.M.; Licciardi, M.; Lombardo, M.; Mandanici, A. Anti-Arrhenian behaviour of conductivity in octanoic acid-bis(2-ethylhexyl)amine systems: A physico-chemical study. J. Mater. Chem. C 2015, 3, 3198-3210. [CrossRef]

129. Uerdingen, M.; Treber, C.; Balser, M.; Schmittc, G.; Wernerb, C. Corrosion behaviour of ionic liquids. Green Chem. 2005, 7, 321-325. [CrossRef]

130. Jimenez, A.E.; Bermudez, M.D.; Carrion, F.J.; Martinez-Nicolas, G. Room temperature ionic liquids as lubricant additives in steel-aluminium contacts: Influence of sliding velocity, normal load and temperature. Wear 2006, 261, 347-359. [CrossRef]

131. Qu, J. Tribological characteristics of aluminum alloys sliding against steel lubricated by ammonium and imidazolium ionic liquids. Wear 2009, 267, 1226-1231. [CrossRef]

132. Bermudez, M.D.; Jimenez, A.E.; Martinez-Nicolas, G. Study of surface interactions of ionic liquids with aluminium alloys in corrosion and erosion-corrosion processes. Appl. Surf. Sci. 2007, 253, 7295-7302. [CrossRef]

133. Gabler, C.; Tomastik, C.; Brenner, J.; Pisarova, L.; Doerra, N.; Allmaierb, G. Corrosion properties of ammonium based ionic liquids evaluated by SEM-EDX, XPS and ICP-OES. Green Chem. 2011, 13, 2869-2877. [CrossRef]

134. Jimenez, A.E.; Bermudez, M.D. Ionic liquids as lubricants of titanium-steel contact part 2: Friction, wear and surface interactions at high temperature. Tribol. Lett. 2010, 37, 431-443. [CrossRef]

135. Kawada, S.; Watanabe, S.; Tsuboi, R.; Sasaki, S.; Prakash, B. Lubrication mechanism of halogen-free ionic liquids. Tribol. Online 2017, 12, 155-161. [CrossRef]

136. Urtis, L.A.; Arcifa, A.; Zhang, P.; Du, J.; Fantauzzi, M.; Rauber, D.; Hempelmann, R.; Kraus, T.; Rossi, A.; Spencer, N.D. Influence of Water on Tribolayer Growth When Lubricating Steel with a Fluorinated Phosphonium Dicyanamide Ionic Liquid. Lubricants 2019, 7, 27. [CrossRef]

137. Smirnova, N.A.; Safonova, E.A. Ionic Liquids as Surfactants. Russ. J. Phys. Chem. A 2010, 84, 1695-1704. [CrossRef]

138. Qi, X.; Zhang, X.; Luo, G.; Han, C.; Liu, C.; Zhang, S. Mixing Behavior of Conventional Cationic Surfactants and Ionic Liquid Surfactant 1-Tetradecyl-3-methylimidazolium Bromide ([C14mim]Br) in Aqueous Medium. J. Dispers. Sci. Technol. 2013, 34, 125-133. [CrossRef]

139. Farooq, U.; Ali, A.; Patel, R.; Malik, N.A. Self-aggregation of ionic liquid-cationic surfactant mixed micelles in water and in diethylene glycol-water mixtures: Conductometric, tensiometric, and spectroscopic studies. J. Mol. Liq. 2017, 234, 452-462. [CrossRef]

140. Calandra, P.; Caschera, D.; Turco Liveri, V.; Lombardo, D. How self-assembly of amphiphilic molecules can generate complexity in the nanoscale. Colloids Surf. A Physicochem. Eng. Asp. 2015, 484, 164-183. [CrossRef]

141. Jinaga, R.; Jagadeesha, T.; Kolekar, S.; Choi, S.-B. The Synthesis of Organic Oils Blended Magnetorheological Fluids with the Field-Dependent Material Characterization. Int. J. Mol. Sci. 2019, 20, 5766. [CrossRef]

142. Schwartz, M. Smart Materials; CRC Press/Taylor \& Francis Group: Boca Raton, FL, USA, 2008; pp. 1-554.

143. Fan, X.; Xia, Y.; Wang, L. Tribological properties of conductive lubricating greases. Friction 2014, 2, 343-353. [CrossRef] 
144. Wang, Z.; Zhu, L.; Si, L.; Ren, X.; Wu, S. Study on the Friction Behaviors of Copper Nanowires in Ionic Liquids under External Voltages. J. Mater. Eng. Perform. 2020, 29, 5718-5727. [CrossRef]

145. Si, L.; Pan, Y.; Zhang, X.; Wang, J.; Yao, J.; Wang, Y.; Liu, F.; He, F. Tribological properties of metallic nanoparticles as lubricant additives under the applied electric currents. Ind. Lubr. Tribol. 2018, 70, 1714-1720. [CrossRef]

146. Gusain, R.; Khatri, O.P. Ultrasound assisted shape regulation of $\mathrm{CuO}$ nanorods in ionic liquids and their use as energy efficient lubricant additives. Mater. Chem. A 2013, 1, 5612-5619. [CrossRef]

147. Carrión, F.J.; Sanes, J.; Bermúdez, M.-D. Effect of the addition of room temperature ionic liquid and ZnO nanoparticles on the wear and scratch resistance of epoxy resin. Wear 2010, 268, 1295-1302.

148. Bermúdez, M.-D.; Brostow, W.; Carrión-Vilches, F.-J.; Sanes, J. Scratch Resistance of Polycarbonate Containing ZnO Nanoparticles: Effects of Sliding Direction. J. Nanosci. Nanotechnol. 2010, 10, 6683-6689. [CrossRef] [PubMed]

149. Rogers, R.D.; Seddon, K.R. Ionic Liquids-Solvents of the Future? Science 2003, 302, 792-793. [CrossRef]

150. European Chemicals Agency (ECHA). Substances Restricted under REACH (Last Updated 10 August 2020). Available online: https:/ / echa.europa.eu/substances-restricted-under-reach (accessed on 1 September 2020).

151. Welton, T. Ionic liquids in Green Chemistry. Green Chem. 2011, 13, 225. [CrossRef]

152. Plechkova, N.V.; Seddon, K.R. Applications of ionic liquids in the chemical industry. Chem. Soc. Rev. 2008, 37, 123-150. [CrossRef] [PubMed]

153. Greer, A.J.; Jacquemin, J.; Hardacre, C. Industrial Applications of Ionic Liquids. Molecules 2020, 25, 5207. [CrossRef] [PubMed]

154. Shiflett, M.B. Commercial Applications of Ionic Liquids; Springer: Cham, Switzerland, 2020; pp. 1-282. 